The National Bureau of Standards' ' was established by an act of Congress March 3, 1901. The Burealu's overall goal is to strengthen and advance the Nation's science and technology and facilitate their effective application for public benefit. To this end, the Bureau conducts research and provides: (1) a basis for the Nation's physical measurement system, (2) scientific and technological services for industry and government, (3) a technical basis for equity in trade, and (4) technical services to promote public safety. The Bureau consists of the Institute for Basic Standards, the Institute for Materials Research, the Institute for Applied Technology, the Institute for Computer Sciences and Technology, and the Office for Information Programs.

THE INSTITUTE FOR BASIC STANDARDS provides the central basis within the United States of a complete and consistent system of physical measurement; coordinates that system with measurement systems of other nations; and furnishes essential services leading to accurate and uniform physical measurements throughout the Nation's scientific community, industry, and commerce. The Institute consists of the Office of Measurement Services, the Office of Radiation Measurement and the following Center and divisions:

Applied Mathematics - Electricity - Mechanics - Heat - Optical Physics - Center for Radiation Research: Nuclear Sciences; Applied Radiation — Laboratory Astrophysics ? - Cryogenics" - Electromagnetics ${ }^{2}$ - Time and Frequency ".

THE INSTITUTE FOR MATERIALS RESEARCH conducts materials research leading to improved methods of measurement, standards, and data on the properties of well-characterized materials needed by industry, commerce, educational institutions, and Government; provides advisory and research services to other Government agencies; and develops, produces, and distributes standard reference materials. The Institute consists of the Office of Standard Reference Materials, the Office of Air and Water Measurement, and the following divisions:

Analytical Chemistry - Polymers - Metallurgy - Inorganic Materials — Reactor Radiation - Physical Chemistry.

THE INSTITUTE FOR APPLIED TECHNOLOGY provides technical services to promote the use of available technology and to facilitate technological innovation in industry and Government; cooperates with public and private organizations leading to the development of technological standards (including mandatory safety standards), codes and methods of test; and provides technical advice and services to Government agencies upon request. The Institute consists of the following divisions and Centers:

Standards Application and Analysis - Electronic Technology - Center for Consumer Product Technology: Product Systems Analysis; Product Engineering - Center for Building Technology: Structures, Materials, and Life Safety; Building Environment; Technical Evaluation and Application - Center for Fire Research: Fire Science; Fire Safety Engineering.

THE INSTITUTE FOR COMPUTER SCIENCES AND TECHNOLOGY conducts research and provides technical services designed to aid Government agencies in improving cost effectiveness in the conduct of their programs through the selection, acquisition, and effective utilization of automatic data processing equipment; and serves as the principal focus within the executive branch for the development of Federal standards for automatic data processing equipment, techniques, and computer languages. The Institute consists of the following divisions:

Computer Services - Systems and Software - Computer Systems Engineering — Information Technology.

THE OFFICE FOR INFORMATION PROGRAMS promotes optimum dissemination and accessibility of scientific information generated within NBS and other agencies of the Federal Government: promotes the development of the National Standard Reference Data System and a system of information analysis centers dealing with the broader aspects of the National Measurement System; provides appropriate services to ensure that the NBS staff has optimum accessibility to the scientific information of the world. The Office consists of the following organizational units:

Office of Standard Reference Data - Office of Information Activities — Office of Technical Publications - Library - Office of International Relations - Office of International Standards.

1 Headquarters and Laboratories at Gaithersburg. Maryland, unless otherwise noted; nailing address Washington, D.C. 20234.

Located at Boulder, Colorado 80302. 


\section{Safe Operation of Capacitance Meters Using. High Applied-Bias Voltage}

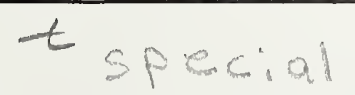

\section{Alvin M. Goodman}

RCA Laboratories

Princeton, New Jersey 08540

This activity was supported by

The Defense Adranced Research Projects Agency

and

The National Bureau of Standards

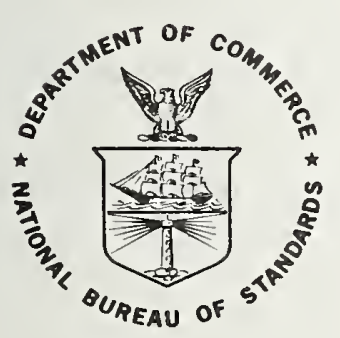

U.S. DEPARTMENT OF COMMERCE, Elliot L. Richardson, Secrefary Edward O. Vetter, Under Secretary

Dr. Betsy Ancker-Johnson, Assistant Secretary for Science and Technology

NATIONAL BUREAU OF STANDARDS, Ernest Ambler, Acting Director

Issued December 1976 
Library of Congress Cataloging in Publication Data

Goodman, Alvin M

Safe operation of capacitance meters using high applied-bias voltage.

(Semiconductor measurement technology) (NBS special publication : 400-34)

Supt. of Docs. no.: C 13.10:400-34

1. Capacitance meters. 2. Electric measurements. 3. High voltages. I. Title. II. Series. III. Series: United States.

National Bureau of Standards.

Special publication : 400-34.

QC100.U57 no. $400-34$ [TK335] 602'.1s [621.37'42]

76- 608338

National Bureau of Standards Special Publication 400-34

Nat. Bur. Stand. (U.S.). Spec Publ. 400-3 1, 57 pages (Dec. 1976)

CODEN: XNBSAV 
CONTENTS

PAGE

1. Introduction ..................... . 1

2. Simplified Circuit and Principles of Operation . . . . . . . 4

3. Actual Circuit ... . . . . . . . . . . 6

3.1. Circuit and Functional Description ........... 6

a. Bias-Protection Circuit ............ 6

b. Zero Adjustment and Zero Suppression . . . . . . 6

c. Peaker Circuit . . . . . . . . . . . . 9

3.2. Measurement Accuracy .............. 10

a. Basic Considerations ............ 10

b. Equivalent Circuit .............. 10

(1) $\mathrm{L}_{\mathrm{X}}=0 \ldots \ldots 11$

(2) $\mathrm{L}_{\mathrm{X}} \neq 0 \ldots \ldots 13$

4. Experimental Results . . . . . . . . . . . . 15

4.1. General . . . . . . . . . . . 15

4.2. Transient Suppression . . . . . . . . . . 15

4.3. Effect of BIU on Measurement Accuracy . . . . . . . 17

5. Discussion and Conclusions . . . . . . . . . . 26

Acknowledgment . . . . . . . . . . . . . . . 27

Appendix . . . . . . . . . . . . . . . . . . 28

References ....................... 49

\section{FIGURE CAPTIONS}

Figure 1. Conventional high-frequency $\mathrm{C}(\mathrm{V})$ measurement. The inset is a schematic illustration of a typical plot of normalized capacitance $\mathrm{C}_{\mathrm{N}}$ versus voltage . . . . . . . . 2 
Figure 2. Isolation box arrangement for measuring $C(V)$ with an applied bias voltage larger than the C-meter limit: (a) block diagram, and (b) isolation box circuit

Figure 3. Simplified version of C-meter bias-protection circuits: (a) normal operating mode, and (b) after a capacitor sample breaks down with a large bias voltage applied to it .......................

Figure 4. Schematic circuit diagram of C-meter bias-isolation unit

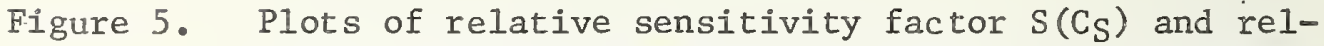
ative incremental sensitivity factor $S^{\prime}\left(C_{S}\right)$ versus $\mathrm{C}_{\mathrm{S}}$ with series resistance $\mathrm{R}$ as a parameter . . . . . 12

Figure 6. (a) Schematic representation of the experimental arrangement for testing the transient suppression capability of the BIU. (b) Photograph of a typical observed transient (HI terminal to ground) . . . . 16

Figure 7. Calibration curves for BIU operating with BEC Model $71 \mathrm{~A}$ C-meter ............... 18

Figure 8. Calibration curves for BIU operating with BEC Model 72AD C-meter

Figure 9. Calibration curves for BIU operating with PAR Model 410 C-meter .............. 20

Figure 10. Relative incremental sensitivity $S^{\prime}\left(C_{S}\right)$ for $B I U$ operating with BEC Model 71A C-meter

Figure 11. Relative incremental sensitivity $S^{\prime}\left(C_{S}\right)$ for BIU operating with BEC Model 72AD C-meter . . . . . .

Figure 12. Relative incremental sensitivity $S^{\prime}\left(C_{S}\right)$ for $B I U$ operating with PAR Model 410 C-meter

Figure 13. Schematic circuit diagram of 3-MHz filter . . . . . 25

Figure MI Front panel Capacitance-Meter Bias-Isolation Unit . • 29

Figure M2 Side panels . . . . . . . . . . . . 30

Figure M3 Rear panel . . . . . . . . . . . . . . 31

Figure M4 Chassis top and bottom covers . . . . . . . . . . 32

Figure M5 Clear acrylic (polymerized methyl methacrylate) base • 33 iv 
Figure Mb́ Peaker/zero suppression shield ......... 34

Figure M7 Drawing containing: A. Shield cover....... 35

B. Shield cover bracket... 35

C. Mounting bracket for L6, L7 - 35

D. PIN diode heat sink ... 35

Figure M8 Physical layout of bridge . . . . . . . 36

Figure M9 Drawing containing: A. Acrylic bias-divider mounting plate ....... 37

B. Acrylic front and rear ... 37

C. Acrylic sides ..... 37

Figure Ml0 Peaker/zero-suppression acrylic mounting bracket . . 38

Figure Mll Zero-suppression fine capacitor acrylic mounting bracket ...................... 39

Figure $\mathrm{Ml} 2$ support . . . . . . . . . . 40

Figure Ml3 Rectifier mounting plate ........... 41

Figure M! Zener heat sink . . . . . . . . . 42

Figure M15 Peaker zero-suppression shield rear insulator . . . 43

Figure Ml6 Acrylic cover insulator ............ . 44

Figure Al Front view of Capacitance-Meter Bias-Isolation Unit . . 45

Figure A2 Top view with top cover removed ......... 46

Figure A3 Top view of Peaker/Zero Suppression circuit with top cover and shield cover removed ........ 47

Figure A4 Bottom view with bottom cover removed ...... 48

\section{LIST OF TABLES}

Table 1. Electrical Parts List for Capacitance-Meter Bias-Isolation Unit . . . . . . . . . . . 8

Table 2. Test-Signal Spectral Analysis for Three C-Meters . . . 26

Table 3. List of Mechanical Parts ........... 28 
This study was carried out at the RCA Laboratories as a part of the Semiconductor Technology Program in the Electronic Technology Division at the National Bureau of Standards. The Semiconductor Technology Program serves to focus NBS efforts to enhance the performance, interchangeability, and reliability of discrete semiconductor devices and integrated circuits through improvements in measurement technology for use in specifying materials and devices in national and international commerce and for use by industry in controlling device fabrication processes. The work was supported by the Defense Advanced Research Projects Agency* through the National Bureau of Standards' Semiconductor Technology Program, Contract 5-35912. The contract was monitored by R. I. Raybold as the Contracting officer's Technical Representative (COTR) and R. Y. Koyama as Assistant COTR.

Certain commercial equipment, instruments, or materials are identified in this report in order to adequately specify the experimental procedure. In no case does such identification imply recommendation or endorsement by the National Bureau of Standards, nor does it imply that the material or equipment identified is necessarily the best available for the purpose.

Larger scale drawings of the mechanical parts are available on request from the COTR, TECH-A-361, National Bureau of Standards, Washington, DC 20234.

*Through ARPA Order 2397, Program Code 6D10. 
SEMICONDUCTOR MEASUREMENT TECHNOLOGY: Safe Operation of Capacitance Meters Using High Applied-Bias Voltage

by

Alvin M. Goodman

Abstract: The use of capacitance meters (C-meters) to determine small-signal (differential) capacitance at $1 \mathrm{MHz}$ as a function of applied-bias voltage is widespread. The maximum value of the bias voltage which may be applied to a sample under test with any commercially available C-meter is $600 \mathrm{~V}$ or less. A larger bias-voltage capability is required for certain applications.

This report describes a technique for using a commercial C-meter with a Bias-Isolation Unit (BIU) for capacitance measurements at bias-voltage magnitudes up to $10 \mathrm{kV}$ without damage to the measurement equipment. The basic principles of operation and the details of the electrical design of a BIU are discussed.

The use of the BIU imposes certain limitations on the range of sample capacitance which may be measured without introducing excessive error. The theory of these limitations is presented and compared with experimental results obtained from the use of the BIU with each of three commercially available C-meters. The measurement capability demonstrated by these results appears to be adequate for all current and future applications. For less than $+1 \%$ error in the indicated (measured) capacitance, the measurable range of the sample capacitance is found to be from 0 to at least $400 \mathrm{pF}$. In some applications, it is important to be able to accurately measure small changes in the sample capacitance; for less than $+1 \%$ error in the indicated (measured) value of a small change in the sample capacitance, the measurable range of the sample capacitance is found to be from 0 to at least $130 \mathrm{pF}$.

Construction details of the BIU are appended.

Key Words: Bias-Isolation Unit; capacitance measurements at high applied-bias voltage; capacitance-meter; extended-range capacitance measurement; high-voltage C(V) measurements; modified MIS C(V) measurements.

\section{INTRODUCTION}

The use of capacitance meters (hereinafter abbreviated as C-meters) to determine small-signal (differential) capacitance as a function of applied-bias voltage is commonplace today in many research, development, and manufacturing applications. Many, if not most, of these applications 
are connected with the semiconductor industry. A variety of commercial instruments* is available to meet most existing measurement requirements.

Typically, an instrument of this type uses a crystal-controlled 1-MHz test signal whose amplitude is $215 \mathrm{mV}$. The test signal is applied to the unknown capacitance; the resulting current is amplified, and its quadrature component (with respect to the applied voltage) is determined using some form of phase-locked synchronous detector. The quadrature component of the current is directly proportional to the measured capacitance, and the C-meter is usually calibrated to read directly in picofarads. In addition, an analog output voltage is generally made available to enable the plotting of capacitance on a recorder. Means are usually provided for applying a quasi-dc bias voltage to the unknown capacitance through the $\mathrm{C}$-meter. This allows the capacitance to be recorded as a function of the applied-bias voltage using the arrangement shown in figure 1. The magnitude of the bias voltage that may be applied in this way is limited. Although the limit differs for different instruments, it is in no case greater than $600 \mathrm{~V}$.

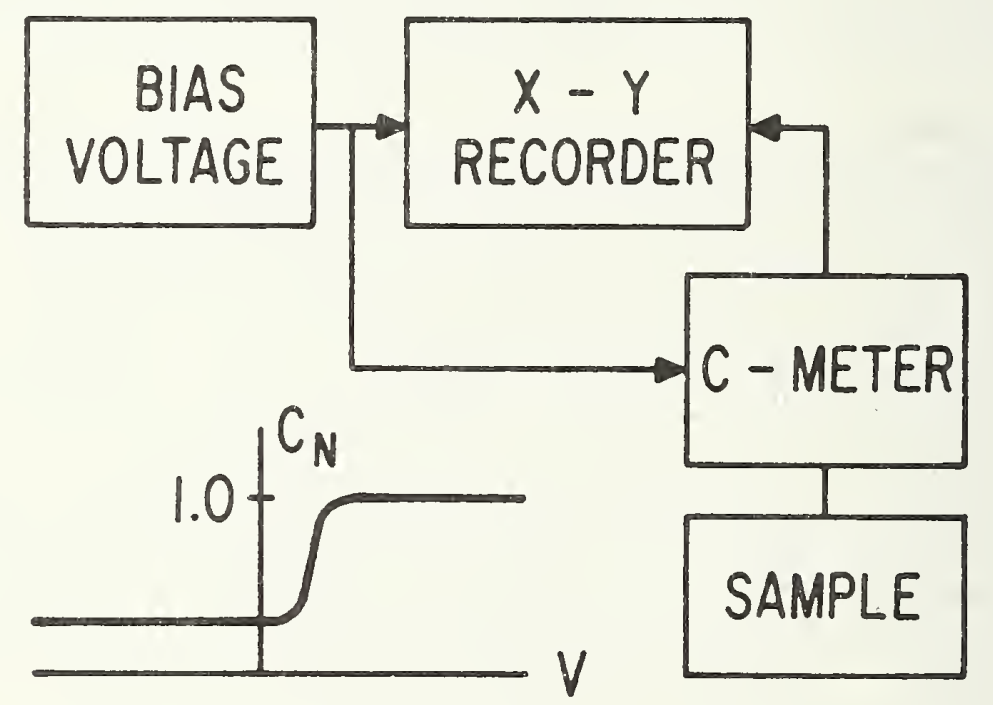

Figure 1. Conventional high-frequency C(V) measurement. The inset is a schematic illustration of a typical plot of normalized capacitance $\mathrm{C}_{\mathrm{N}}$ versus voltage.

It is sometimes necessary to apply a bias voltage larger than $600 \mathrm{~V}$ to a capacitor sample $[1,2]$. This can be accomplished by using an arrangement which applies the bias directly to the sample but not to the C-meter. An example (based on a circuit described in reference 3) is shown in figure 2. The isolation box allows the bias voltage to be

* Some examples of commercial C-meters (or instruments containing C-meters) are as follows: BEC (Boonton Electronics Corporation) Models 71A, 71AR, 72A, 72AD, 72B, 72BD; and PAR (Princeton.Applied Research Corporation) Mode1 410. 


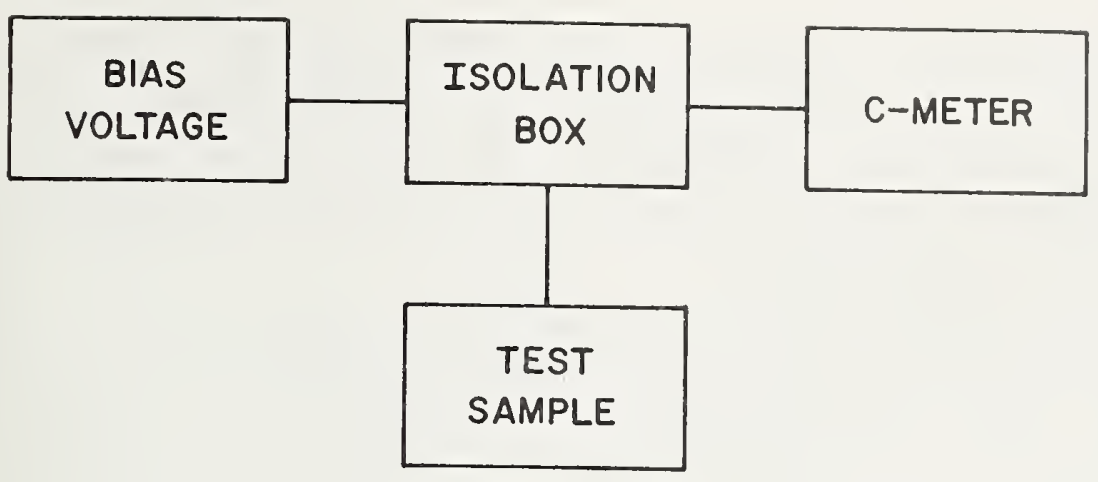

(a) BLOCK DIAGRAM

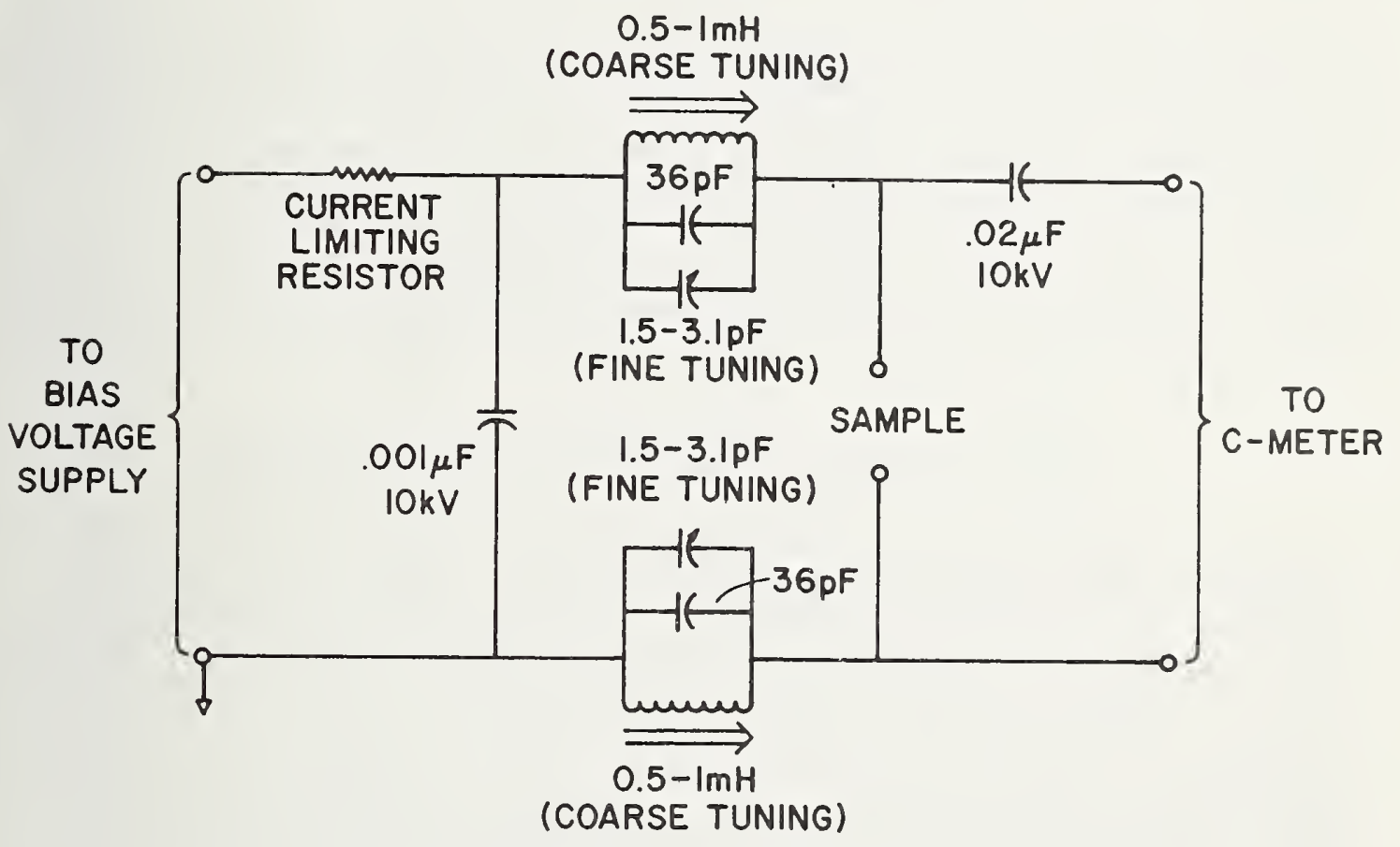

(b) ISOLATION BOX CIRCUIT

Figure 2. Isolation box arrangement for measuring $C(V)$ with an applied bias voltage larger than the C-meter limit: (a) block diagram, and (b) isolation box circuit.

applied to the sample while keeping it out of the C-meter; at the same time, it isolates the bias-voltage supply from the high-frequency test signal. It is assumed that there is a dc path through the C-meter to allow the high-voltage-blocking capacitor to charge and discharge as the bias voltage is (slowly) varied. The parallel resonant circuits are tuned to the test frequency ( $1 \mathrm{MHz}$ in this case) to provide the necessary ac isolation. This isolation can also be obtained by using sufficiently high-value resistors instead of the tuned circuits. The 
blocking capacitor between the sample and the C-meter must be sufficiently large that it does not introduce unacceptable error into the measurement. For the value shown $(0.02 \mu \mathrm{F})$, the maximum error for samples with $\mathrm{C} ₹ 100 \mathrm{pF}$ would be $₹ 0.5 \%$. The voltage rating of the blocking capacitor must, of course, be at least as large as the greatest anticipated bias voltage.

The arrangement shown in figure 2 does not, however, provide complete protection for the C-meter in the case of sample failure. If the sample develops a short-circuit while a large bias voltage is applied to it, the blocking capacitor (which is also charged up to the bias voltage) must discharge through the C-meter. If the voltage across the blocking capacitor just before the sample "shorts" is sufficiently large, the C-meter will be damaged.

In order to prevent this type of damage to the C-meter, a "bias-protection circuit" has been developed. The basic principles of this circuit and some of the design considerations are discussed in section 2. The actual circuit and operation of a C-meter "Bias-Isolation Unit" (BIU), which allows safe capacitance measurements at bias voltage up to $\pm 10 \mathrm{kV}$, are described in section 3. In section 4, some of the experimental results obtained using the BIU with commercial C-meters are presented. Finally, in section 5, present and possible future applications of capacitance measurements at high applied-bias voltage are discussed.

\section{SIMPLIFIED CIRCUIT AND PRINCIPLES OF OPERATION}

The operation of the C-meter bias-protection circuit can best be described by considering a simplified version: first, in the normal operating mode, as shown in figure $3(\mathrm{a})$, and second, the equivalent circuit after a sample "breaks down" with a large bias voltage applied to it, as shown in figure $3(\mathrm{~b})$. The sample capacitance being measured is represented by $C_{S}$. The series combination of $L$ and $C_{B}$ is tuned to resonance (at the measurement frequency of the $\mathrm{C}$-meter) so that there is no reactance in series with $C_{S}$. The diodes $D$ exhibit very small capacitance and conductance at the measurement signal level ( $\sim$ millivolts) and thus do not interfere with the measurement of $\mathrm{C}_{\mathrm{S}}$. The shunt capacitance and conductance of the diodes can be reduced still further by applying a small reverse bias to each of the diodes. The value of $\mathrm{R}$ is much less than $\mathrm{X}_{\mathrm{CS}}$, and in a first approximation its effect on the measurement of $\mathrm{C}_{S}$ may be ignored. A detailed consideration of its effect will be presented later. The bias voltage is supplied to $\mathrm{C}_{S}$ through high-value resistances $\left(r>X_{C S}\right)$; they serve two functions: (i) to effectively isolate the bias supply from the measurement circuit, and (ii) to limit the current in case of a sample breakdown (short circuit).

The C-meter is represented by a parallel RLC circuit at the measurement frequency. There is a low-resistance dc path between the terminals of the c-meter. This allows the dc voltage at the C-meter terminal to remain effectively zero during slow variations of the applied-bias voltage. 


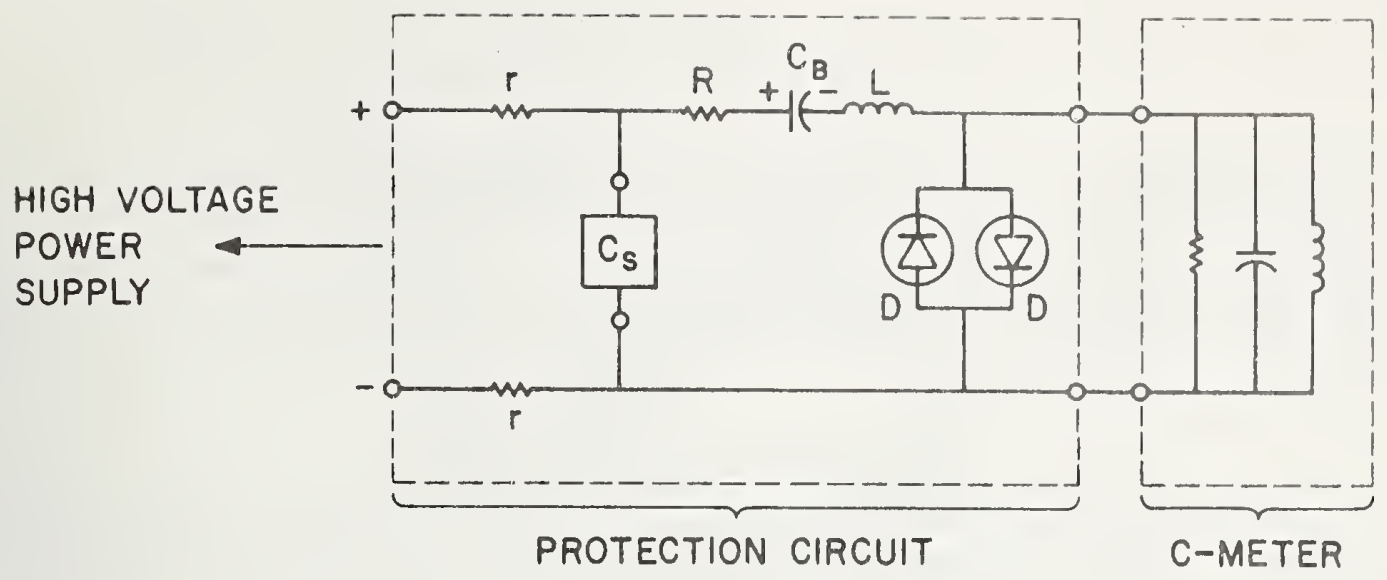

(a)

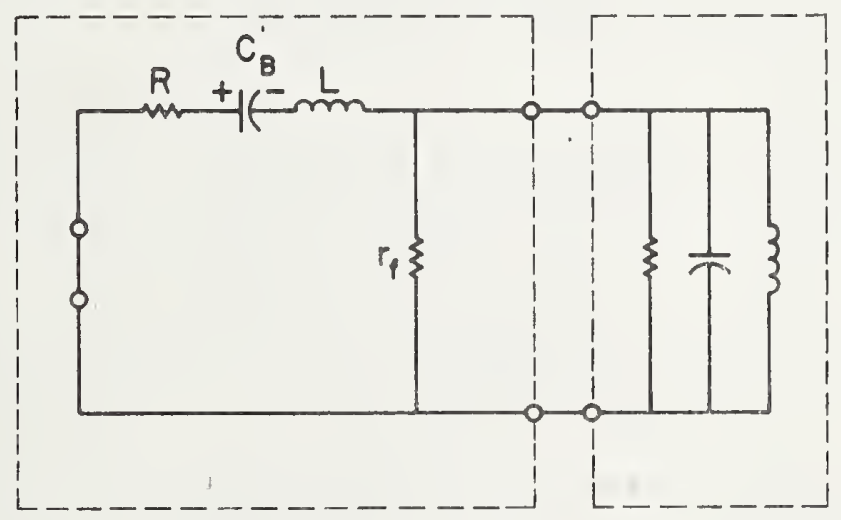

(b)

Figure 3. Simplified version of C-meter bias-protection circuits: (a) normal operating mode, and (b) after a capacitor sample breaks down with a large bias voltage applied to it.

During large rapid variations of the sample bias-voltage, the voltage at the C-meter terminals would start to become significantly different from zero; one or the other of the diodes would then start to conduct heavily when biased in the forward direction. One rather important example of rapid variation of sample bias-voltage is the case in which the sample develops a short-circuit during application of a large bias voltage; the voltage across the sample drops (almost) instantaneously to zero and $C_{B}$ must discharge through $R$, $L$, and the parallel combination of the diodes and the C-meter. This is illustrated schematically in figure $3(\mathrm{~b})$. The forward resistance of the conducting diode $\mathrm{r}_{\mathrm{f}}$ 'must be sufficiently low that the voltage at the input terminals of the C-meter never exceeds the maximum allowable value; i.e., it remains "clamped" within some allowable range. 


\section{ACTUAL CIRCUIT}

\subsection{Circuit and Functional Description}

The schematic circuit diagram of the C-meter bias-isolation unit (hereinafter abbreviated as BIU) is shown in figure 4 and the individual circuit elements are described in table 1. The circuit performs not only the bias-protection function but a number of others as well; these will now be described.

\section{a. Bias-Protection Circuit}

The high and low terminals of the output to the C-meter are individually clamped by diodes (D1 and D2 on the high side, D3 and D4 on the low side) to remain within some allowable range with respect to ground. The diodes D1 through D4 are PIN diodes with a low forward resistance, high reverse resistance, and fast turn-on. To reduce their loading effect on the $\mathrm{C}$-meter, they are normally maintained at a reverse bias of $6.8 \mathrm{~V}$. The bias voltages $(+6.8$ and $-6.8 \mathrm{~V}$ ) are provided with a very low source impedance by the Zener diodes, VRI and VR2.

The high-voltage blocking capacitors C3 and C4 are at (or nearly at) series resonance at $1 \mathrm{MHz}$ with $\mathrm{L} 1+\mathrm{L} 6$ and $\mathrm{L} 2+\mathrm{L} 7$, respectively. Adjustment of L6 and L7 can be used to compensate for series inductance of the connecting leads both inside and outside the BIU.

The voltage dividers formed by $\mathrm{R} I$ and $\mathrm{R} 8$ on the HIGH side and $\mathrm{R} 2$ and $\mathrm{R} 9$ on the LOW side serve to attenuate the bias input by a factor of 1000:1 so that it may be fed directly to the $\mathrm{X}$-axis of an $\mathrm{X}-\mathrm{Y}$ recorder.

High-frequency noise from the bias supply is attenuated by the low-pass filter formed by $\mathrm{R} 5, \mathrm{R} 6$, and $\mathrm{C} 1$. The resistors $\mathrm{R} 3$ and $\mathrm{R} 4$ and the capacitor Cl form a filter isolating the bias supply from the 1-MHz measurement signal.

A bias voltage equal to that at the high side of the sample is available at J5 for application to a guard ring electrode. The 1-MHz series resonant circuit formed by $\mathrm{L} 3$ and $\mathrm{C} 2$ assures that the guard ring is effectively grounded at the measurement signal frequency.

\section{b. Zero Adjustment and Zero Suppression}

In order to facilitate the nulling ("canceling out") of capacitance between the high side and low side test terminals, a circuit (labeled ZERO SUPPRESSION in figure 4) has been provided to allow a wide range of zero adjustment. This is useful not only for the usual nulling of stray capacitance due to sample holder and/or connecting leads but also for operation of the $\mathrm{C}$-meter in a suppressed-zero mode as is required for "modified MIS C(V) measurements" [1,2]. 


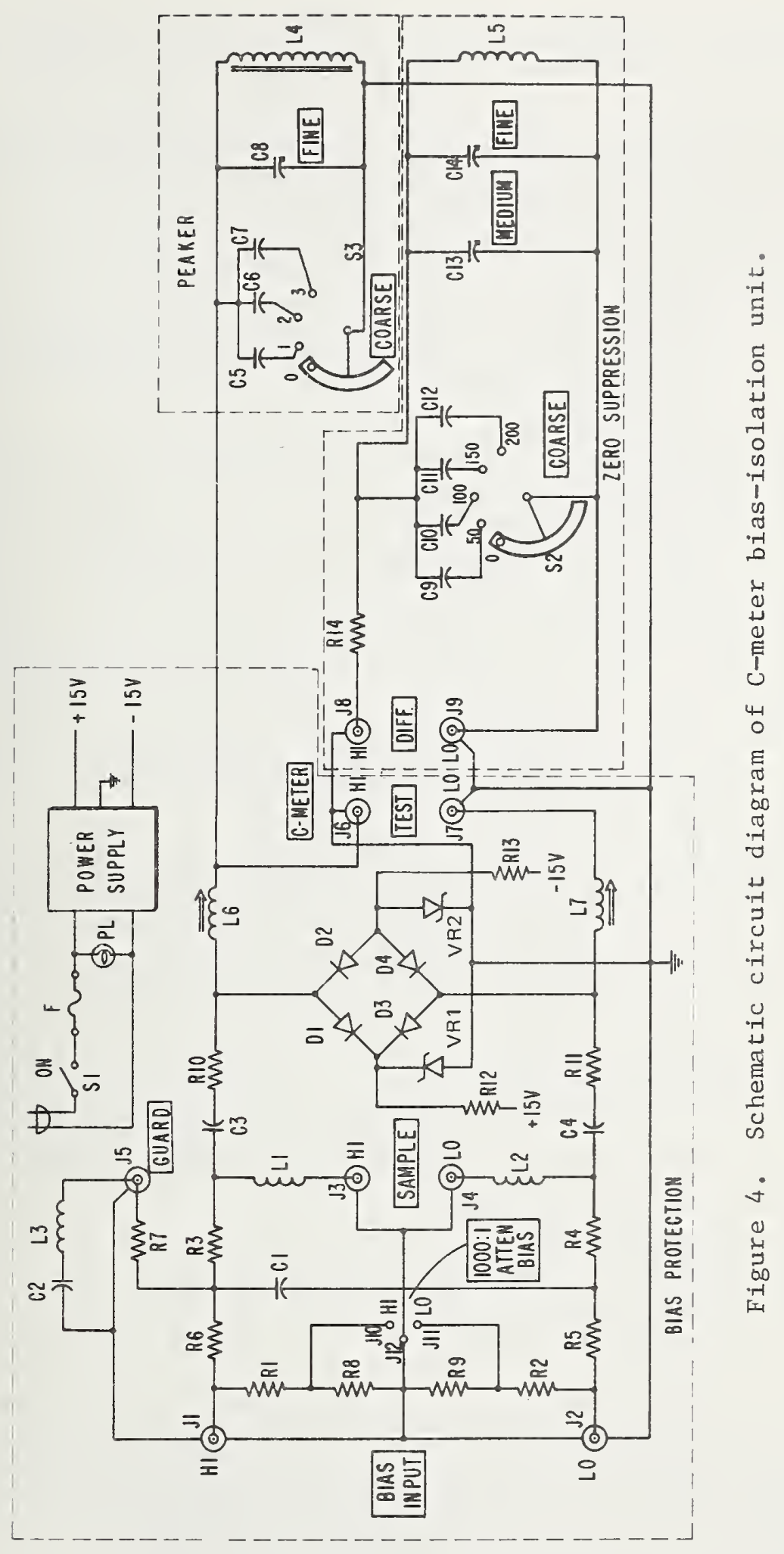




\section{Table 1. Electrical Parts List for Capacitance-Meter Bias-Isolation Unit}

Schematic Reference

R1, R2

R3, R4

R5 , R6

R7

R8, R9

$\mathrm{R} 10, \mathrm{R} 11$

R12, R13

$\mathrm{R} 14$

$\mathrm{Cl}$

$\mathrm{C} 2, \mathrm{C} 3, \mathrm{C4}$

$\mathrm{C} 5, \mathrm{C} 6, \mathrm{C} 7$

$\mathrm{C} 8, \mathrm{C} 13$

$\mathrm{C}, \mathrm{C} 10, \mathrm{C} 11$,

$\mathrm{C} 12$

C14

D1, D2, D3,

D4

L1, L2

L 3

L4

L5

L6, L7

$\mathrm{J} 1, \mathrm{~J} 2, \mathrm{~J} 3$,

$\mathrm{J} 4$, J5

J6, J7, J8,

J9

J10, J11, J12

S1

$\mathrm{S2}, \mathrm{S3}$

VR1

VR2

Fuse

Power Supply
Description (Commercial designation, * if appropriate, shown in parentheses)

$48.8 \times 10^{6}-\Omega$ nominal value, "high-voltage stable"; series string of 17 resistors: $2.87 \times 106 \Omega, 1 \%$, T2.

$5 \times 10^{6} \Omega, 1 \%, 12.5 \mathrm{~W}$, "high-voltage stable."

$4.7 \times 10^{5} \Omega, 10 \%, 2 \mathrm{~W}$.

$4.7 \times 10^{6} \Omega, 10 \%, 2$ W.

$51,350-\Omega$ nominal value. Actual values are obtained by selecting resistor combinations that will result in $1000: 1$ bias voltage attenuation at J10 and Jll when those terminals are shunted by the input impedance of the recorder $(106 \Omega)$.

$25-\Omega$, "high-voltage stable"; serles string of 25 resistors: $1-\Omega, 3-W$ noninductive.

$820 \Omega, 10 \%, 2 \mathrm{~W}$.

$51 \Omega, 1 \%, 1 / 2 \mathrm{~W}$, noninductive.

$0.01 \mu \mathrm{F}, 14 \mathrm{kVDCW}$ (Plastic Capacitors, Type HG 140-103).

$0.002 \mu \mathrm{F}, 14 \mathrm{kVDCW}$ (Plastic Capacitors, Type HG 140-202).

$36 \mathrm{pF}$ silvered mica capacitor.

5.2 - 75 pF variable capacitor (E. F. Johnson, Type "L", No. 167-0004-001).

51 pF silvered mica capacitor.

2.2 - $10 \mathrm{pF}$ variable capacitor with speed-reducing planetary drive. (E. F. Johnson Type "L", No, 167-0001-001) (Jackson Brothers, Type 4511/DAF planetary ball drive with $6: 1$ ratio).

PIN diodes (Unitrode, Type 7201D diodes).

Special choke, 33 turns wound on 1 in. dia. $\times 4$ in. length plastic form. Special choke, $\sim 50$ turns wound on 1 in. dia. $\times 4$ in. length plastic form to resonate with $\mathrm{C} 2$ at $1 \mathrm{MHz}$.

$145 \mu \mathrm{H}$, high Q choke (Boonton Electronics Corp., Type 400124).

$1000 \mu \mathrm{H}$.

1.2 to $2.5 \mu \mathrm{H}$ (North Hills, Type 120A with 3 turns removed leaving

12 turns remaining).

High voltage coaxial chassis connector (Amphenol, Type 97-3102A-18-420S).

Insulated BNC coaxial chassis connector (Amphenol, Type 31-010).

Insulated banana jack.

SPST toggle switch.

Ceramic insulated continuous shorting type switch.

Type IN3305B Zener diode.

Type IN3305RB Zener diode.

Type 3AG-1A.

Regulated with + and $-15 \mathrm{~V}$ outputs (Semiconductor Circuits, Type 2.15.100).

\footnotetext{
*The commercial designations listed above are for components whose dimensions are consistent with those of the mechanical parts described in the appendix. The use of other components may require modification of the mechanical parts on which they are mounted. This commerctal Identification of components does not imply recommendation or endorsement by the National Bureau of Standards nor does 1 t 1 mply that these components are necessarily the best avallable for the purpose.
} 
The circuit consists of a variable amount of capacitive susceptance that is applied between the high side test terminal and a source of voltage* which is approximately equal to the test signal in magnitude but is $180 \mathrm{deg}$ out of phase with it. A range of greater than $250 \mathrm{pF}$ of zero suppression is available. In order that this range include "zero" (i.e., no zero suppression) the minimum value of C13 + C14 plus the stray capacitance of the wiring must be "canceled out" by a small inductive susceptance (L5). The resistor R14 is approximately equal to the sum of $\mathrm{R} 10+\mathrm{R} 11$ to minimize the phase imbalance between the signals applied to the high-side input terminal of the C-meter during operation in a suppressed-zero mode.

\section{c. Peaker Circuit}

A C-meter with a high-impedance input is sensitive to loading due to stray capacitance from the (high side) input terminal to ground. There is in the BEC Models 71A/71AR an adjustable tuned circuit that provides inductive susceptance from the high side input terminal to ground; this circuit may be used to null (or compensate) up to about $100 \mathrm{pF}$ of stray capacitance. The BIU, sample holder, and connecting cables may provide more stray capacitance than can be nulled by this circuit. Therefore, an additional circuit providing inductive susceptance has been built into the BIU for use if needed; it is capable of nulling up to an additional $150 \mathrm{pF}$. This portion of the circuit is labeled PEAKER in figure 4. In operation the PEAKER is adjusted as follows:

(i) With the cables and sample connected, the C-meter is set to its highest sensitivity (highest input impedance).

(ii) The ZERO SUPPRESSION control is set to produce a reading in the upper half of the scale.

(iii) The PEAKER is then adjusted to obtain a maximum reading. If the meter goes off-scale, repeat steps (ii) and (iii).

The peaker circuit adjustment is important only when the C-meter used has a high input impedance. If the C-meter has a low-impedance input like the PAR Model 410, its performance will be completely indifferent to adjustment of the peaker circuit.

The capacitor to be measured is connected to the terminals marked SAMPLE and the bias-voltage power supply is connected to the terminals marked BIAS INPUT. If a guard-ring electrode system is to be used on the sample, the guard ring is connected to the terminal marked GUARD and the guarded electrode must be connected to the HIGH side; the unguarded electrode is connected to the LOW side.

If the BIU is used with a BEC C-meter, the TEST and DIFF terminals of the Cometer are connected to the correspondingly marked terminals of of the BIU. The external bias terminals of the C-meter should be connected together (short-circuited).

*This voltage is available at the LO side of the terminals marked DIFF on BEC Models and at the terminal marked NULL on the PAR Model 410. 
If the BIU is used with a PAR Model $410 \mathrm{C}$-meter, the HI side of the TEST and DIFF terminals of the BIU should be connected together and to the C-meter terminal marked INPUT. The LO side of the TEST and DIFF terminals of the BIU should be connected, respectively, to the C-meter terminals marked DRIVE and NULL.

\subsection{Measurement Accuracy \\ a. Basic Considerations}

The use of the BIU places certain constraints upon the range of test capacitance values which can be measured and the accuracy with which these measurements can be made. In what follows we shall first consider a simple equivalent circuit for the combination of the test capacitance and the BIU, and second, derive expressions describing the deviation of the apparent or "measured" capacitance from the actual value as a function of the equivalent circuit parameters.

\section{b. Equivalent Circuit}

The C-meter measures the capacitive susceptance of a test capacitance $\mathrm{C}_{\mathrm{S}}$ connected between its terminals and displays this value on a suitably calibrated linear scale reading directly in units of capacitance (usually picofarads). Let us define this value of susceptance as:

$$
B_{0}\left(C_{S}\right) \equiv \omega C_{S}
$$

When the C-meter is used with the BIU to measure the same test capacitance, the equivalent circuit is one in which the test capacitance appears to be in series with a resistance $R$ and (possibly) a reactance $x$. The resistance is due principally to the sum of R10 + R11 in figure 4 . There may also be a small contribution due to the resistance in the windings of L1, L2, L6, and L7 and in the blocking capacitors C3 and C4. The reactance $X$ is equal to the difference between the inductive reactance of the sum of the circuit inductances (L1 + L2 + L6 + L7 + lead inductance) and the capacitive reactance of the series combination of $\mathrm{C} 3$ and C4. We shall see shortly that there is no advantage to X being capacitive (negative); in practice, we would like it to be either zero or slightly inductive. We shall therefore treat it as if it were due to an "excess" inductance $\mathrm{LX}_{\mathrm{X}}$.

The susceptance $B\left(C_{S}\right)$ of the series combination of $C_{S}, R$, and $L_{X}$ measured by the $\mathrm{C}$-meter is

$$
B\left(C_{S}\right)=\frac{\omega C_{S}\left[1-\omega^{2} L_{X} C_{S}\right]}{\omega^{2} R^{2} C_{S}{ }^{2}+\left[1-\omega^{2} L_{X} C_{S}\right]^{2}}
$$

We may now define a relative sensitivity factor, $S\left(C_{S}\right)$. 


$$
S\left(C_{S}\right) \equiv \frac{B\left(C_{S}\right)}{B_{0}\left(C_{S}\right)}=\frac{\left[1-\omega^{2} L_{X} C_{S}\right]}{\omega^{2} R^{2} C_{S}{ }^{2}+\left[1-\omega^{2} L_{X} C_{S}\right]^{2}}
$$

This gives the ratio of the apparent value of the $C_{S}$ that would be indicated by the C-meter when used with the BIU to the actual value of $\mathrm{C}_{\mathrm{S}}$ that would be indicated by the C-meter alone. In some measurement applications [1,2] it is necessary to determine small changes in a test capacitance. It is, therefore, of interest to derive an expression for the relative incremental sensitivity factor which we shall call $\mathrm{S}^{\prime}\left(\mathrm{C}_{\mathrm{S}}\right)$.

$$
\begin{aligned}
& S^{\prime}\left(C_{S}\right) \equiv \frac{d B\left(C_{S}\right)}{d C_{S}} / \frac{d B_{0}\left(C_{S}\right)}{d_{S}} \\
& S^{\prime}\left(C_{S}\right)=\frac{\left[1-\omega^{2} L_{X} C_{S}\right]^{2}-\omega^{2} R^{2} C_{S}{ }^{2}}{\left[\left(1-\omega^{2} L_{X} C_{S}\right)^{2}+\omega^{2} R^{2} C_{S}{ }^{2}\right]^{2}}
\end{aligned}
$$

This gives the ratio of the apparent value of a small change in $\mathrm{C}_{\mathrm{S}}$ that would be indicated by the C-meter when used with the BIU to the actual value of the small change in $\mathrm{C}_{S}$ that would be indicated by the $\mathrm{C}$-meter alone. Ideally, of course, both $S$ and $S^{\prime}$ should be equal to 1.0 for all values of $C_{S}$, but this could be true only for both $L_{X}$ and $R$ equal to zero; i.e., without the protection circuit to which $\mathrm{R}$ is essential.

It is helpful to consider two separate regimes (a) $L_{X}=0$ and (b) $L_{X} \neq 0$. (1) $\mathrm{L}_{\mathrm{X}}=0$

In this regime, eqs (3) and (4b) reduce to

$$
S\left(C_{S}\right)=\frac{1}{1+\omega^{2} R^{2} C_{S}^{2}}
$$

and

$$
S^{\prime}\left(C_{S}\right)=\frac{1-\omega^{2} R^{2} C_{S}{ }^{2}}{\left[1+\omega^{2} R^{2} C_{S}{ }^{2}\right]^{2}}
$$

In figure 5, $S$ and $S^{\prime}$ are plotted as a function of $C_{S}$ with $R$ as a parameter. For the value $R=50$, it $c$ an be seen that the added error in measurement due to the BIU should be less than $1 \%$ in $S$ for $\mathrm{C}_{\mathrm{S}} \approx 300 \mathrm{pF}$ and less than $1 \%$ in $S^{\prime}$ for $\mathrm{C}_{\mathrm{S}} \approx 180 \mathrm{pF}$. These ranges of $\mathrm{C}_{\mathrm{S}}$ measurable with low added error far exceed any application requirements encountered to date. 


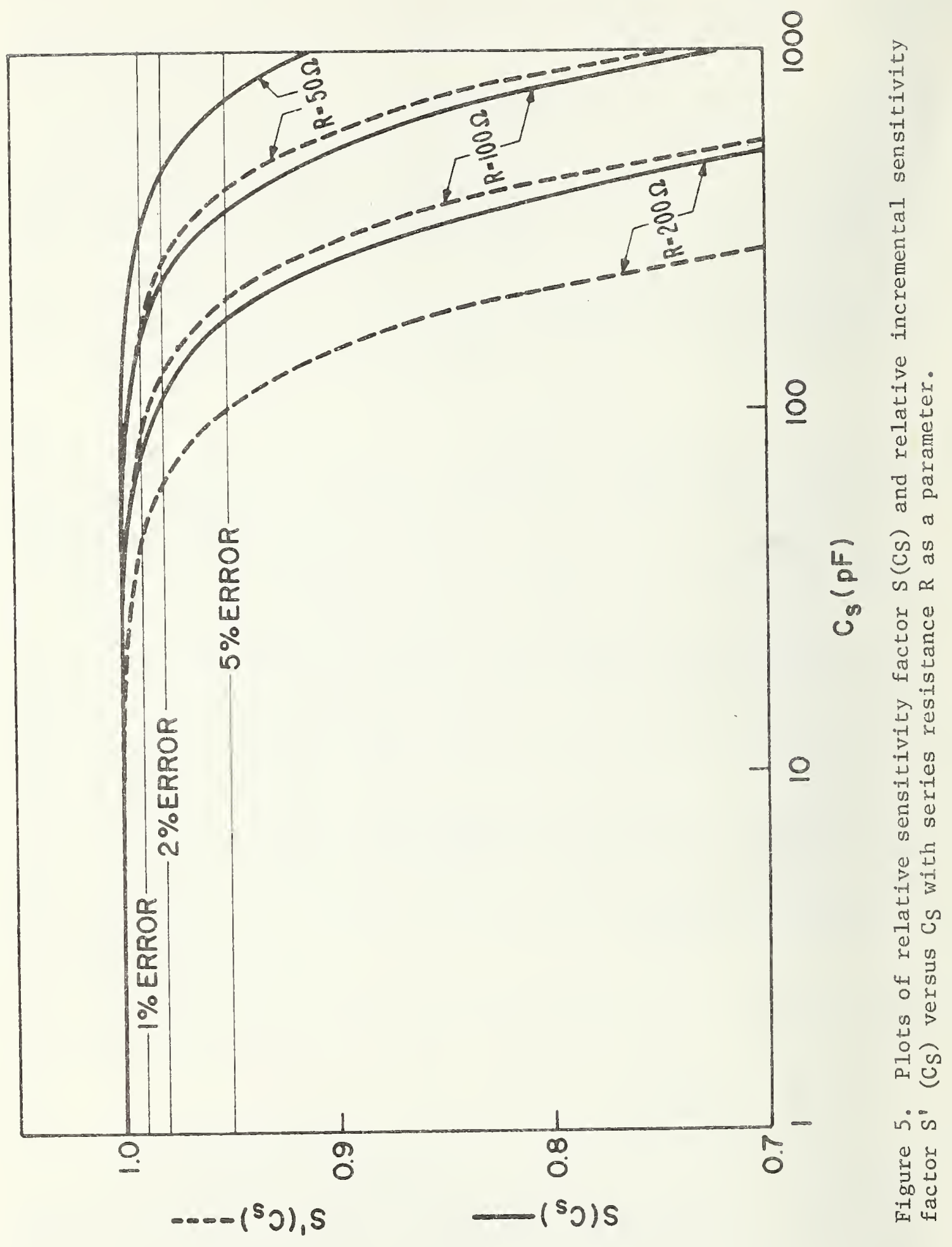


(2) $\mathrm{L}_{\mathrm{X}} \neq 0$

It is helpful to write eqs (3) and (4b) in the form

$$
S\left(C_{S}\right)=\frac{1-\alpha C_{S}}{\left(1-\alpha C_{S}\right)^{2}+\beta C_{S}{ }^{2}}
$$

and

$$
S^{\prime}\left(C_{S}\right)=\frac{\left[1-\alpha C_{S}\right]^{2}-\beta C_{S}{ }^{2}}{\left[\left(1-\alpha C_{S}\right)^{2}+\beta C_{S}{ }^{2}\right]^{2}}
$$

where $\alpha=\omega^{2} L_{X}$ and $\beta=\omega^{2} R^{2}$.

We are particularly interested in the region in which $S\left(C_{S}\right)$ and $S^{\prime}\left(C_{S}\right)$ are close to 1 ; i.e., the region in which $\alpha C_{S}<<1$ and $B C_{S}{ }^{2}<<1$. Equations (5a) and (5b) may be simplified by carrying out the indicated operations and retaining only first-order terms in $\alpha C_{S}$ and $\beta C_{S}{ }^{2}$. This gives

$$
S\left(C_{S}\right) \doteq I+\alpha C_{S}-\beta C_{S}^{2}
$$

and

$$
S^{\prime}\left(C_{S}\right) \doteq I+2 \alpha C_{S}-3 \beta C_{S}^{2}
$$

For non-zero $\alpha$, both $S\left(C_{S}\right)$ and $S^{\prime}\left(C_{S}\right)$ are increasing functions of $C_{S}$ at low values of $\mathrm{C}_{\mathrm{S}}$, go through maxima and become decreasing functions of $\mathrm{C}_{\mathrm{S}}$. These maxima may be found by differentiating eqs (7a) and (7b) and setting them equal to zero. This gives

$$
\begin{gathered}
\mathrm{S}\left(\mathrm{C}_{\mathrm{S}}\right)_{\max }=1+\beta \mathrm{C}_{\mathrm{S}}{ }^{2} \\
\text { at } \mathrm{C}_{\mathrm{S}}=\alpha / 2 \beta
\end{gathered}
$$

and

$$
\begin{gathered}
S^{\prime}\left(C_{S}\right)_{\text {max }}=1+3 \beta C_{S}{ }^{2} \\
\text { at } C_{S}=\alpha / 3 \beta
\end{gathered}
$$

It was previously stated that there is no advantage to the reactance $X$ being capacitive (negative); that this is true can be seen from the following argument. If the reactance were negative, the terms in eqs (7a) and ( $7 b$ ) which are linear in $C_{S}$ would become negative and the 
departure of $S\left(C_{S}\right)$ and $S^{\prime}\left(C_{S}\right)$ from their ideal values of 1.00 would occur more rapidly with increasing $\mathrm{C}_{\mathrm{S}}$. This is clearly undesirable.

It is easily demonstrated that for a given allowable error magnitude in either $\mathrm{S}\left(\mathrm{C}_{\mathrm{S}}\right)$ or $\mathrm{S}^{\prime}\left(\mathrm{C}_{\mathrm{S}}\right)$, a wider range of measurable $\mathrm{C}_{\mathrm{S}}$ can be obtained by using an "appropriate" value of $\alpha\left(\mathrm{L}_{X}\right)$ than would be possible for $\alpha=0$.

Let us consider two examples. First, we consider the case in which the maximum allowable error in $S\left(C_{S}\right)$ is $\pm \varepsilon$. At its maximum value, $\mathrm{S}\left(\mathrm{C}_{\mathrm{S}}\right)_{\max }=1+\varepsilon$. It follows from eq $\mathrm{s}(8 \mathrm{a})$ and $(8 \mathrm{~b})$ that the appropriate value of $\alpha$ is

$$
\alpha(\varepsilon)=2 \sqrt{\beta \varepsilon}
$$

The maximum value and, therefore, the maximum range of $\mathrm{C}_{S}$ which can be measured without exceeding the allowable error $\varepsilon$, is found from eqs (7a) and (9) to be

$$
\Delta C_{S}(\alpha, \varepsilon)=[1+\sqrt{2}][\varepsilon / \beta]^{1 / 2}
$$

This may be compared with the maximum range of $\mathrm{C}_{\mathrm{S}}$ which can be measured without exceeding the allowable error in $S\left(C_{S}\right)$ when $\alpha=0$, i.e., when there is no excess inductance; in this case the range is

$$
\Delta C_{S}(O, \varepsilon)=[\varepsilon / \beta]^{1 / 2}
$$

Thus, the appropriate value of $\alpha$ can provide an increase in measurable range of $\mathrm{C}_{\mathrm{S}}$ by a factor of

$$
\frac{\Delta C_{S}(\alpha, \varepsilon)}{\Delta C_{S}(0, \varepsilon)}=1+\sqrt{2}
$$

As a second example, we consider the case in which the maximum allowable error in $S^{\prime}\left(C_{S}\right)$ is $\pm \varepsilon^{\prime}$. At its maximum value, then, $S^{\prime}\left(C_{S}\right)=1+\varepsilon^{\prime}$. It follows from eqs $(8 c)$ and (8d) that the appropriate value of $\alpha$ for this case is

$$
\alpha\left(\varepsilon^{\prime}\right)=\sqrt{3 \beta \varepsilon^{\prime}}
$$

The maximum value and, therefore, the maximum range of $\mathrm{C}_{\mathrm{S}}$ which can be measured without exceeding the allowable error $\varepsilon^{\prime}$ is found from eqs (7b) and (13) to be

$$
\Delta C_{S}\left(\alpha, \varepsilon^{\prime}\right)=[1+\sqrt{2}][\varepsilon / 3 \beta]^{1 / 2}
$$

This may be compared with the maximum range of $\mathrm{C}_{S}$ which can be measured without exceeding the allowable error in $S^{\circ}\left(C_{S}\right)$ when $\alpha=0$, i.e., when there is no excess inductance; in this case the value is 


$$
\Delta C_{S}\left(0, \varepsilon^{\prime}\right)=[\varepsilon / 3 \beta]^{1 / 2}
$$

Here again, there is an increase in the measurable range of $\mathrm{C}_{\mathrm{S}}$ by a factor of

$$
\frac{\Delta \mathrm{C}_{\mathrm{S}}\left(\alpha, \varepsilon^{\prime}\right)}{\Delta \mathrm{C}_{\mathrm{S}}\left(0, \varepsilon^{\prime}\right)}=1+\sqrt{2}
$$

Note, however, that the "appropriate" values of $\alpha$ are not the same for equal error magnitudes $\varepsilon$ and $\varepsilon^{\prime}$.

In summary then, excess inductance $\mathrm{L}_{X}$ can be used to increase the measurable range of $C_{S}$ without exceeding a set of preassigned error limits on either $S\left(C_{S}\right)$ or $S^{\prime}\left(C_{S}\right)$.

\section{EXPERIMENTAL RESULTS}

\subsection{Genera1}

The BIU described in section 3 was tested to ensure that it would properly perform the desired bias-protection (transient-suppression) function and that the accuracy of measurements made with it would not be excessively degraded. These tests and their results will now be described.

\subsection{Transient Suppression}

The experimental arrangement for testing the transient-suppression capability of the BIU is shown in figure 6. A test capacitor periodical1y short-circuiting under high bias $(10 \mathrm{kV})$ is simulated by a motordriven spark gap. The resulting transient voltage at the C-meter terminals is picked up with a probe and displayed on a fast oscilloscope. The voltage from each C-meter terminal to ground was checked individually for each polarity of applied bias and found to have a peak value less than $\pm 200 \mathrm{~V}$. A typical example is shown in figure $6(\mathrm{~b})$.

In addition, repeated sample breakdowns were simulated under actual test conditions; i.e., with a C-meter connected. These tests were conducted with three different types of commercially available C-meters: (i) a BEC Model 71A, (ii) a BEC Model 72AD, and (iii) a PAR Model 410. The $\mathrm{C}$-meters were tested before and after the simulated breakdowns; no damage or change in calibration was found.

Furthermore, many actual sample breakdowns have occurred during $C(V)$ measurements using the BIU at high voltage levels (approaching $10 \mathrm{kV}$ ). In none of these breakdowns was a C-meter damaged. 


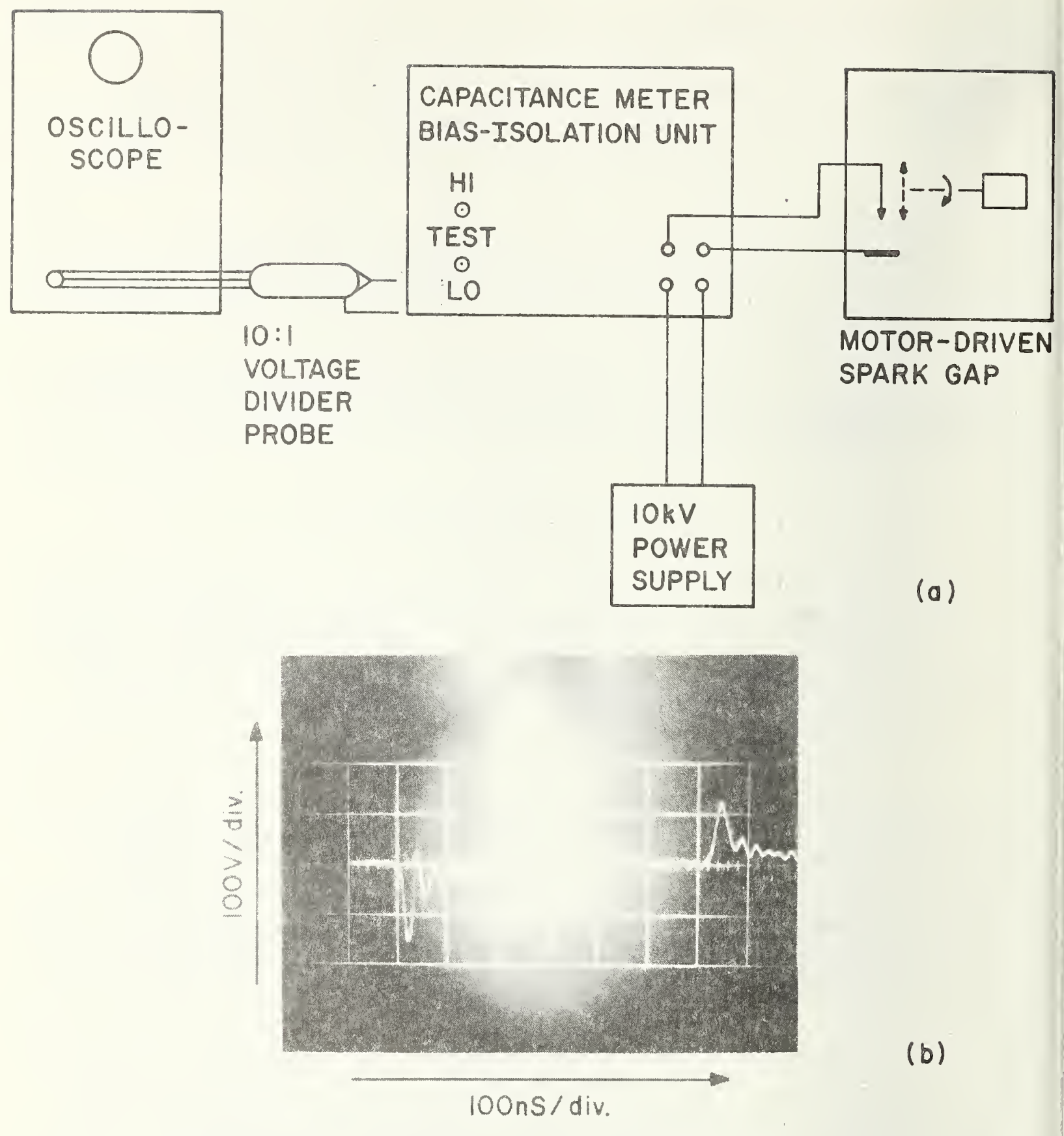

Figure 6. (a) Schematic representation of the experimental arrangement for testing the transient suppression capability of the BIU. (b) Photograph of a typical observed transient (HI terminal to ground). 


\subsection{Effect of the BIU on Measurement Accuracy}

In section 3.2 the effect of the BIU on the accuracy of C-meter measurement was considered from a theoretical point of view. The actual effect was determined experimentally by measuring $S\left(C_{S}\right)$ and $S^{\prime}\left(C_{S}\right)$ for each of the three $\mathrm{C}$-meters used in the transient suppression tests (section 4.2). Prior to these measurements L6 and L7 were adjusted to produce minimum reactance at $1 \mathrm{MHz}$ between the terminals $\mathrm{J} 3$ and $\mathrm{J} 6$ and between $\mathrm{J} 4$ and $\mathrm{J} 7$ of figure 4. That is, there was no intentional use of excess inductance to "stretch" the measurable range of $\mathrm{C}_{\mathrm{S}}$. Some slight additional inductance was, of course, present due to the leads connecting the BIU to the C-meter and the test capacitor to the BIU.

In order to measure $S\left(C_{S}\right)$ and $S^{\prime}\left(C_{S}\right)$, a precision decade capacitor was used as a standard. This 3-terminal capacitance standard has an accuracy of $0.25 \%$ for each of its component capacitors. In each case, the output of the C-meter was read on the 10-inch scale of an $\mathrm{X}-\mathrm{Y}$ recorder with an accuracy of $0.2 \%$ of full scale. Each C-meter was calibrated on the appropriate scale(s) by connecting the standard capacitor directly to the C-meter (i.e., with BIU out of the circuit), and following the manufacturer's calibration instructions.

After the completion of the calibration procedure, the standard capacitor was connected to the $\mathrm{C}$-meter through the BIU, and the apparent capacitance (as measured through the BIU) was determined as a function of the standard capacitance.

From section $3.2 \mathrm{~S}\left(\mathrm{C}_{\mathrm{S}}\right)=$ apparent value of $\mathrm{C}_{\mathrm{S}} /$ standard value of $\mathrm{C}_{\mathrm{S}}$.

It was not possible to obtain $S^{\prime}(C S)$ directly. Therefore, the following approximation was used: $S^{\prime}\left(C_{S}\right) \stackrel{\circ}{=}$ (measured increase in the apparent value of $C_{S}$ due to an actual increase of $\left.\delta C_{S}\right) / \delta C_{S}$. For a11 of the measurements discussed in this report, $\delta \mathrm{C}_{\mathrm{S}}=1 \mathrm{pF}$. The actual measurement procedure was as follows: (i) a value of $\mathrm{C}_{\mathrm{S}}$ was set on the standard capacitor, (ii) the output was reduced to zero using the ZERO SUPPRESSION controls, (iii) the sensitivity of the recorder was increased by a factor such that an additional $1 \mathrm{pF}$ should cause full-scale deflection on the recorder, (iv) the output was again adjusted to zero, (v) the standard capacitor was increased by $1 \mathrm{pF}$, and ( $v i$ ) the value of $S^{\prime}\left(C_{S}\right)$ was read directly from the recorder with full scale corresponding to $S^{\prime}=1.00$; if the deflection exceeded full scale by more than $1 \%$ (the available recorder over-range) the sensitivity was reduced by a factor of $1 / 2$, in which case half-scale deflection corresponded to $S^{\prime}=1.00$.

Measurements of apparent capacitance versus standard capacitance were carried out using each $\mathrm{C}$-meter, and the value of $\mathrm{S}\left(\mathrm{C}_{\mathrm{S}}\right)$ was computed for each data point. The results are shown in figures 7, 8, and 9. For comparison, the theoretical expression, eq (5) for $S\left(C_{S}\right)$ based on the simplified equivalent circuit with $\mathrm{L}_{\mathrm{X}}=0$, is also shown in each figure. Qualitatively, the results are similar for the three C-meters, viz., the falloff of $S\left(C_{S}\right)$ with increasing $C_{S}$ is smaller than would be expected from eq (5) over most of the measured range of $\mathrm{C}_{S}$. This occurs undoubtedly because the connecting leads provide a small excess inductance 


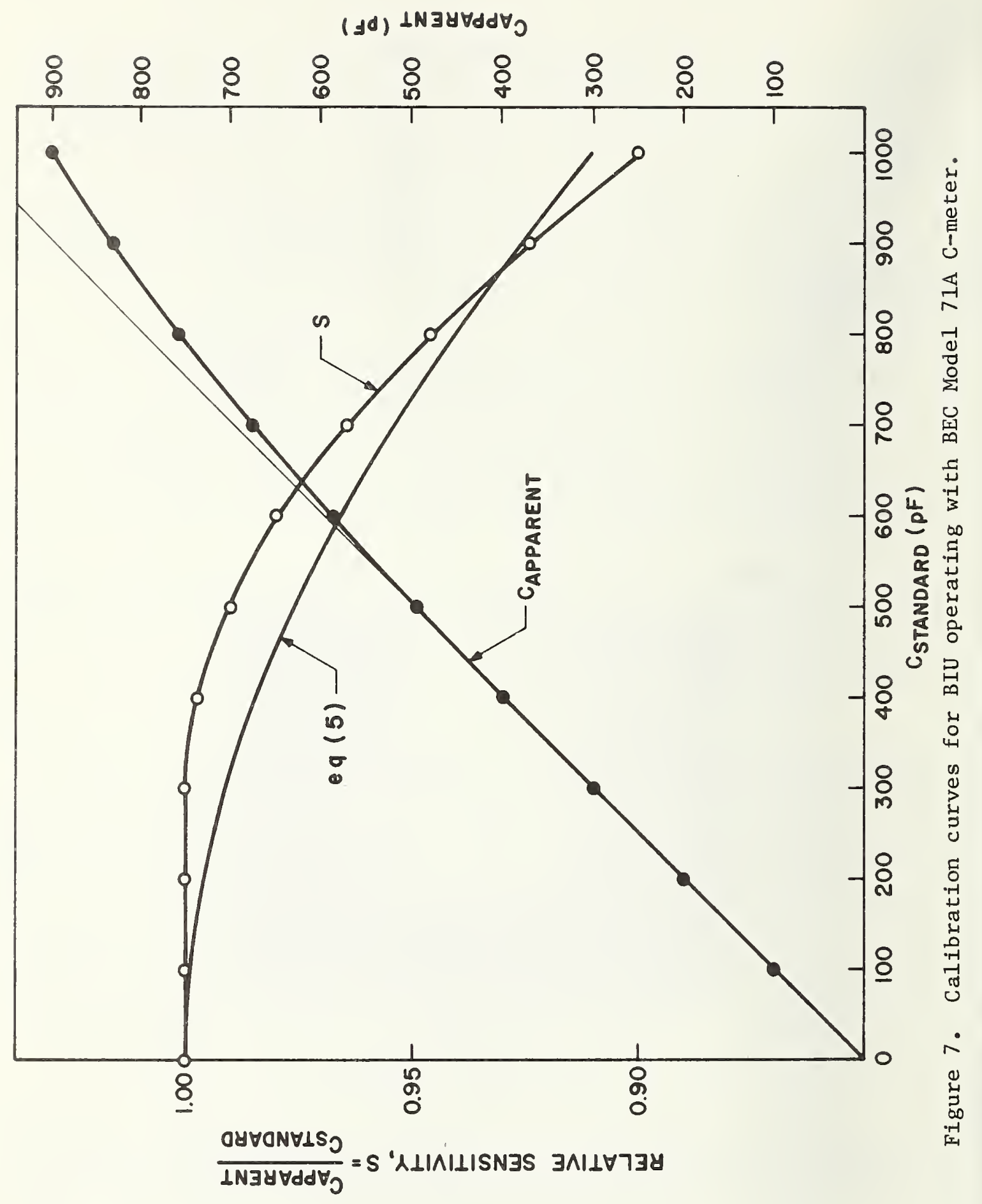




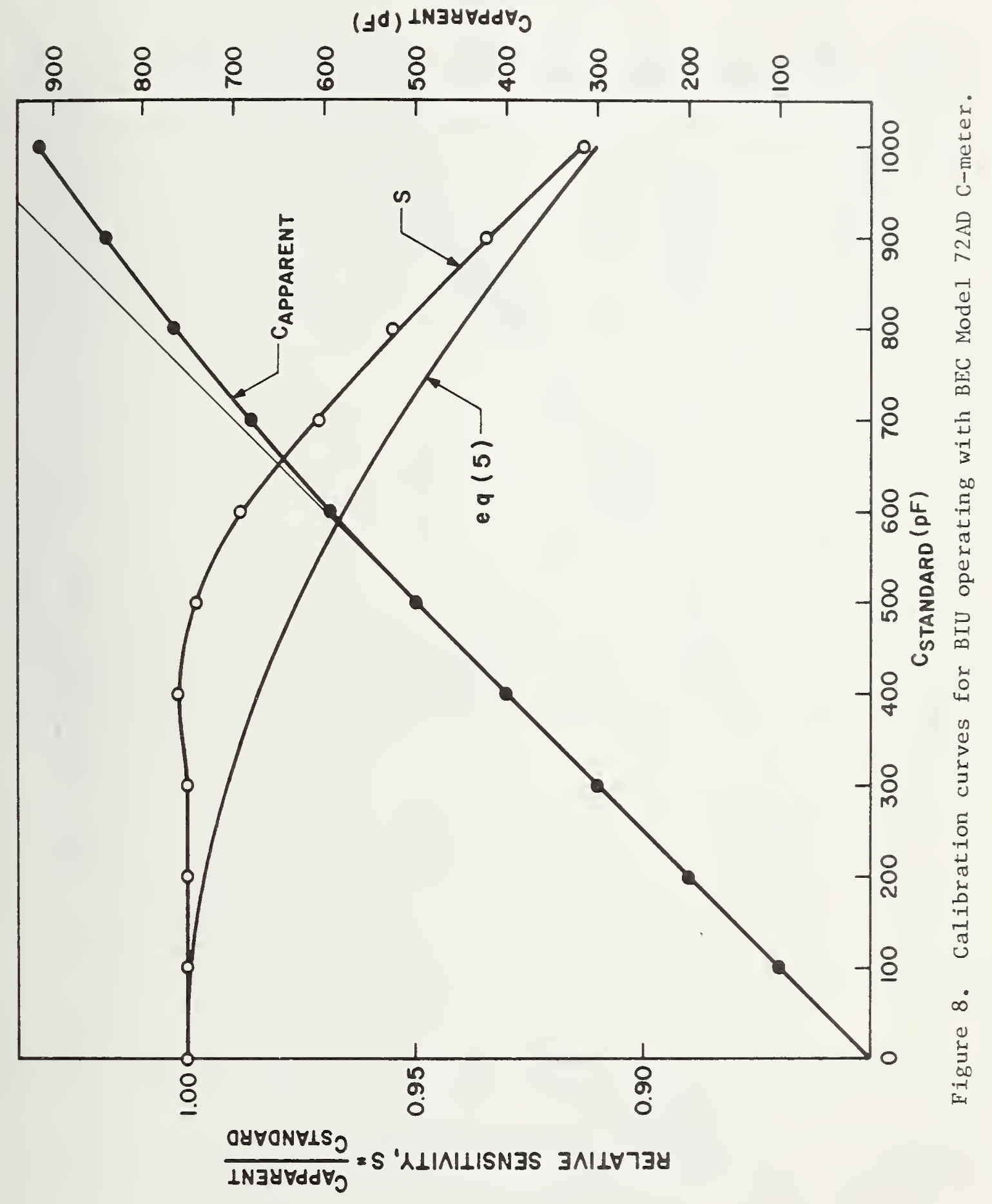




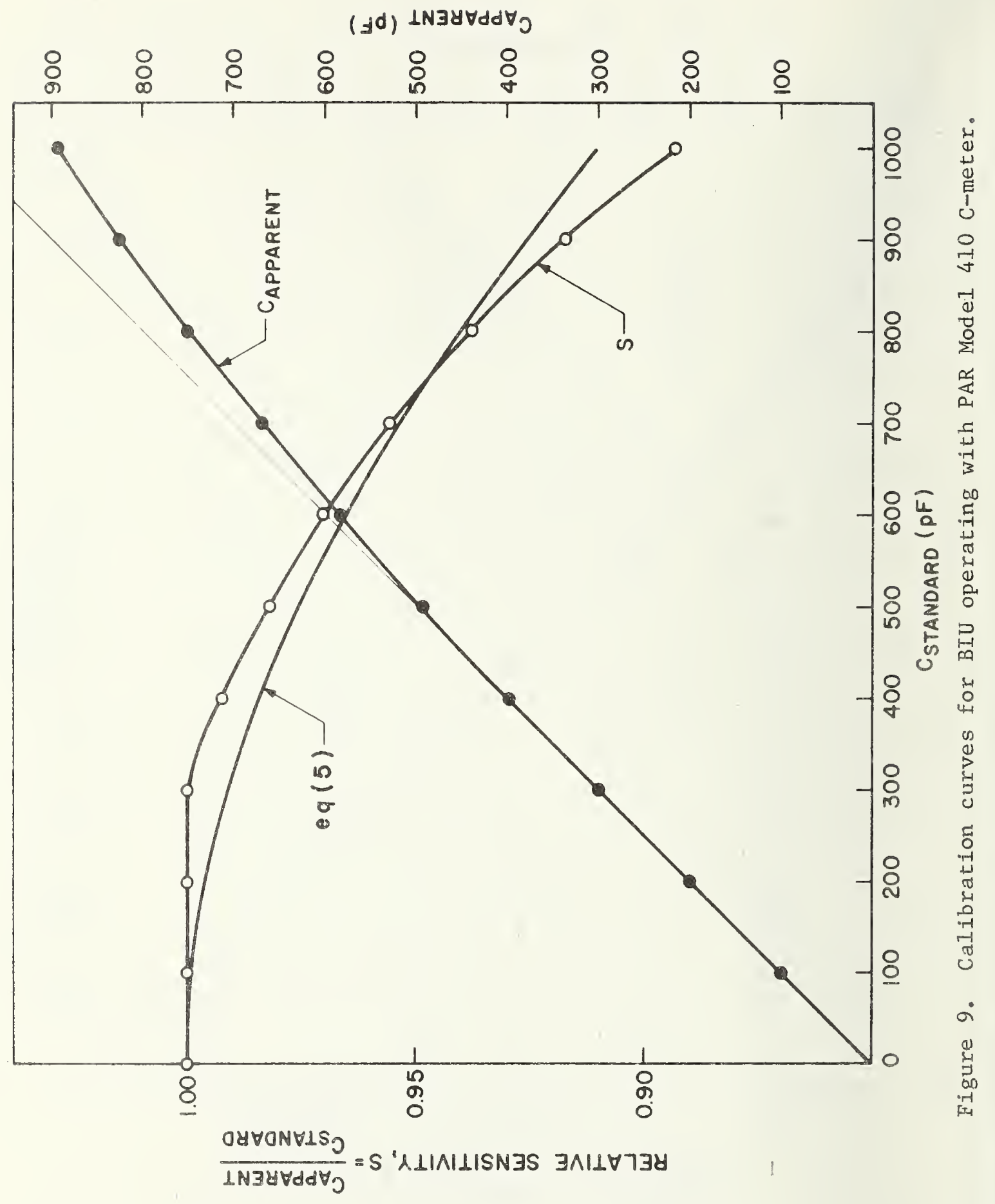


$\mathrm{L}_{\mathrm{X}}$, having the effect discussed in section 3.2. This is most evident in the data for the Boonton Model 72AD C-meter (see fig. 8), where there is a detectable peak in $S\left(C_{S}\right)$.

There is one other deviation from $S\left(C_{S}\right)=1.00$ using the BEC Mode1 71A. This occurs on the lower capacitance ranges where the input resistance is high. On the 1,3 , and $10 \mathrm{pF}$ scales, $\mathrm{S}\left(\mathrm{C}_{\mathrm{S}}\right)$ was $0.892,0.968$, and 0.995, respectively, independent of $\mathrm{C}_{\mathrm{S}}$. This falloff in sensitivity is due to the loading of the input circuit by the BIU. The effect is not detectable on the $30 \mathrm{pF}$ and higher capacitance ranges. The effect is not a serious one in any case since it is independent of $\mathrm{C}_{\mathrm{S}}$ and may easily be compensated by an appropriate internal adjustment of the Cmeter sensitivity on the lower scales (if the C-meter is dedicated to operation with the BIU) or, alternatively, by appropriately adjusting the recorder sensitivity. The input impedance of each of the other two C-meters tested is sufficiently low that they are not loaded by the BIU on any scale.

The value of $S^{\prime}\left(C_{S}\right)$ was then determined for each of the C-meters. The results are plotted as open circles in figures 10, 11, and 12 . The other data in figures 11 and 12 will be discussed shortly. For comparison, each figure also shows the theoretical expression, eq (6), for $S^{\prime}\left(C_{S}\right)$ based on the simplified equivalent circuit with $L_{X}=0$. The results for the three C-meters are distinctly different in this case.

For the BEC Model 71A C-meter (see fig. 10) the experimentally determined values of $S^{\prime}\left(C_{S}\right)$ rise above 1.0 at 1 ow $C_{S}$ and fall below 1.0 at higher $\mathrm{C}_{\mathrm{S}}$. The initial rise is thought to be due to the excess inductance provided by the connecting leads. Above $\mathrm{C}_{\mathrm{S}} \approx 120 \mathrm{pF}$, the experimental values of $\mathrm{S}^{\prime}\left(\mathrm{C}_{\mathrm{S}}\right)$ fall off more rapidly with increasing $\mathrm{C}_{\mathrm{S}}$ than would be expected from eq (6). There are probably two reasons for this:

(i) The measurements were made using the $100 \mathrm{pF}$ scale corresponding to an input resistance of approximately $60 \Omega$; as $\mathrm{C}_{\mathrm{S}}$ and the zero-suppression capacitance are increased, the effective capacitance from the HI terminals to ground increases, shunting the $60-\Omega$ input resistance and lowering the apparent sensitivity of the C-meter.

(ii) The effective series resistance of the BIU may be larger than $50 \Omega$ due to the series resistance contribution of the coils and blocking capacitors.

Nevertheless, there is a measurement range of $140 \mathrm{pF}$ in $\mathrm{C}_{\mathrm{S}}$ in which $\mathrm{S}^{\prime}$ does not deviate from its ideal value of 1.0 by more than $1 \%$.

For the BEC Model 72AD C-meter (see fig. 11), the initial experimental results (unfilled circles) were rather bizarre. Similar results were obtained from the initial experimental measurements (unfilled circles in fig. 12) of $S^{\prime}\left(C_{S}\right)$ using the PAR Model 410 C-meter. The undulation of $S^{\prime}\left(C_{S}\right)$ suggested the possibility of resonances occurring at frequencies other than the $1-\mathrm{MHz}$ test signal. An analysis of the equivalent circuit at harmonics of $1 \mathrm{MHz}$, taking into account the value of $\mathrm{CS}_{\mathrm{S}}$ at 


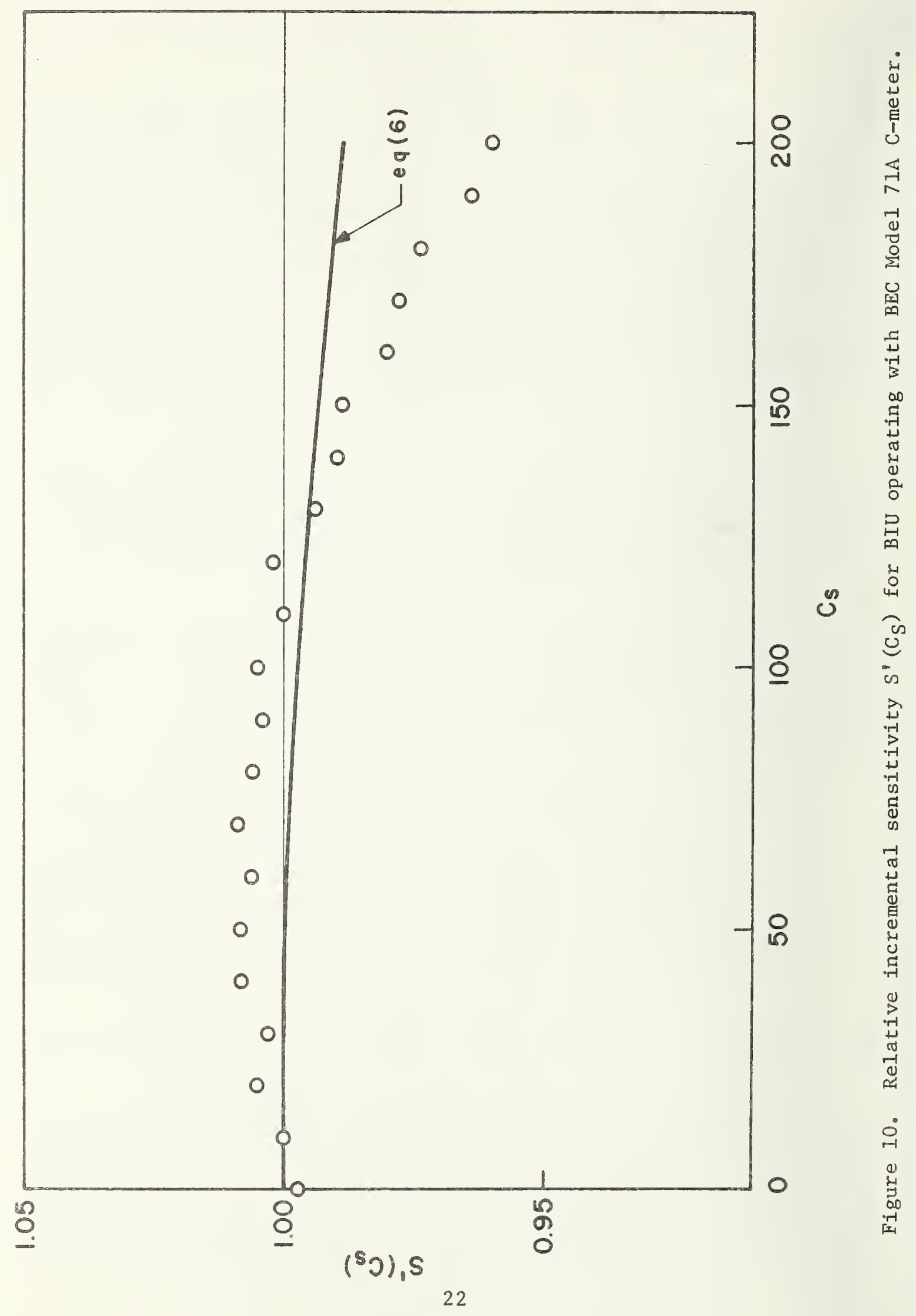




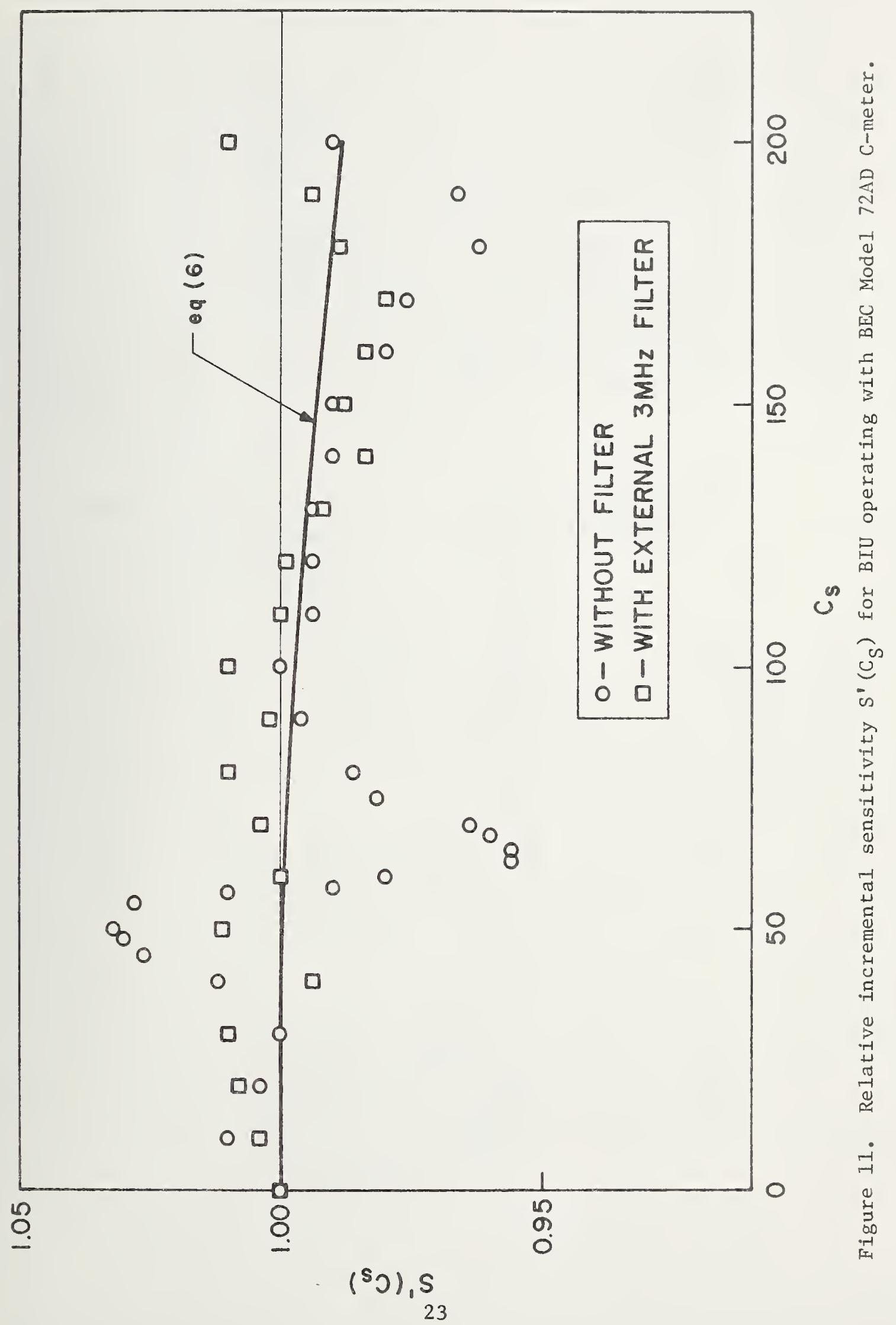




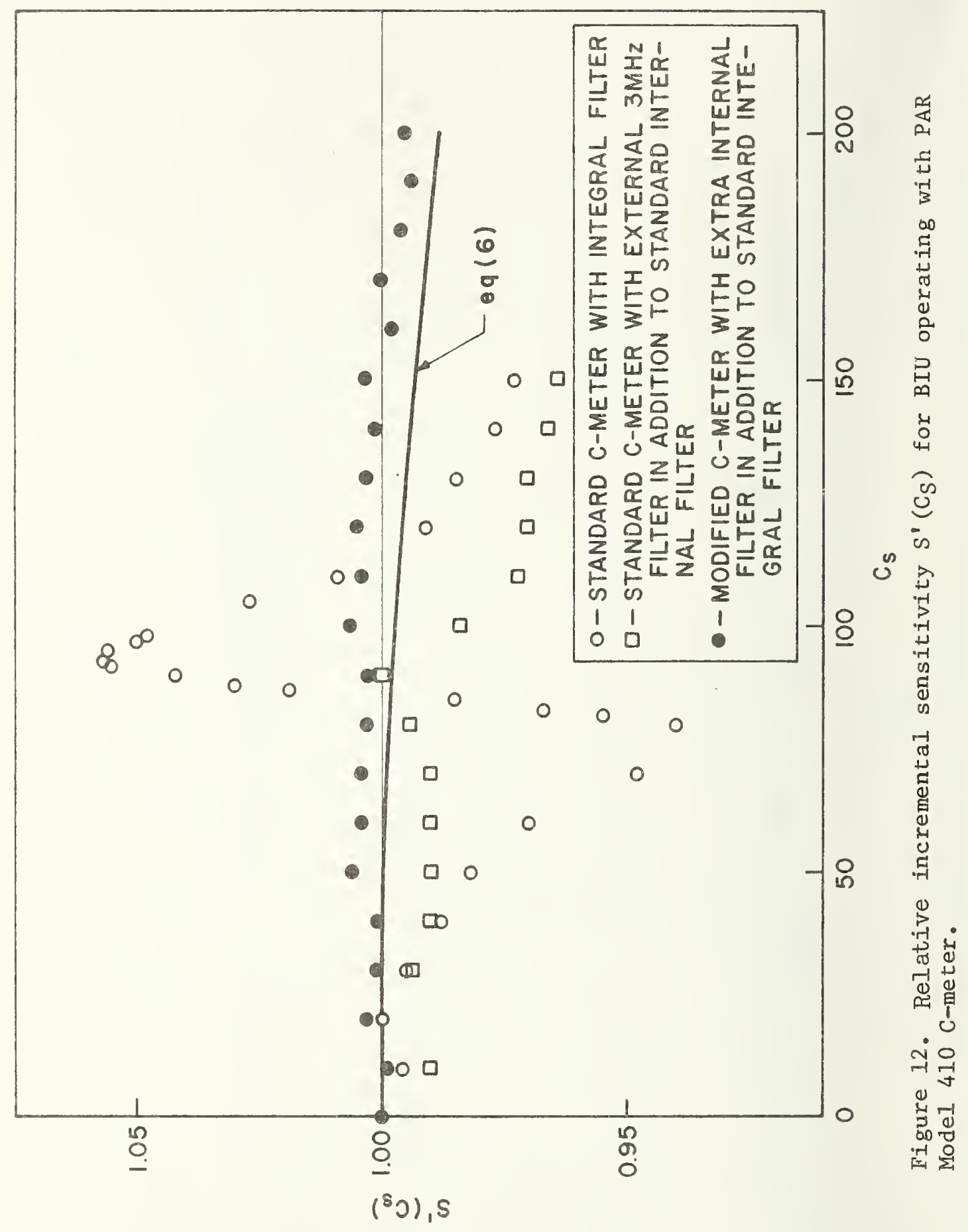


which the largest undulation takes place, indicated that the major culprit was probably a third-harmonic component in the test signal. To test this hypothesis, a crude filter was assembled for use between the BIU and the C-meter (fig. 13). The purpose of the filter was to attenuate the third-harmonic component of the current flowing from the test capacitor $\mathrm{CS}_{\mathrm{S}}$ into the $\mathrm{C}$-meter $\mathrm{HI}$ terminal. The measurements of $S^{\prime}\left(C_{S}\right)$ were repeated for the BEC Model 72AD and PAR Model $410 \mathrm{C}-$ meters using the filter. The results are shown as the squares in figures 11 and 12. It was clear that the filter provided a substantial improvement in the 0 to $100 \mathrm{pF}$ range of $\mathrm{C}_{S}$; it was equally clear that further improvement was desirable. For this reason, a spectral analysis of the test signal of each of the three C-meters was carried out. The results (shown in table 2) indicate that the BEC Model 71A has the "cleanest" test signal, while the test signals of the other two are relatively rich in harmonics. These results confirmed that the unexpected behavior of $\mathrm{S}^{\prime}\left(\mathrm{C}_{S}\right)$ was indeed due to the presence of undesirable harmonics in the test signal.

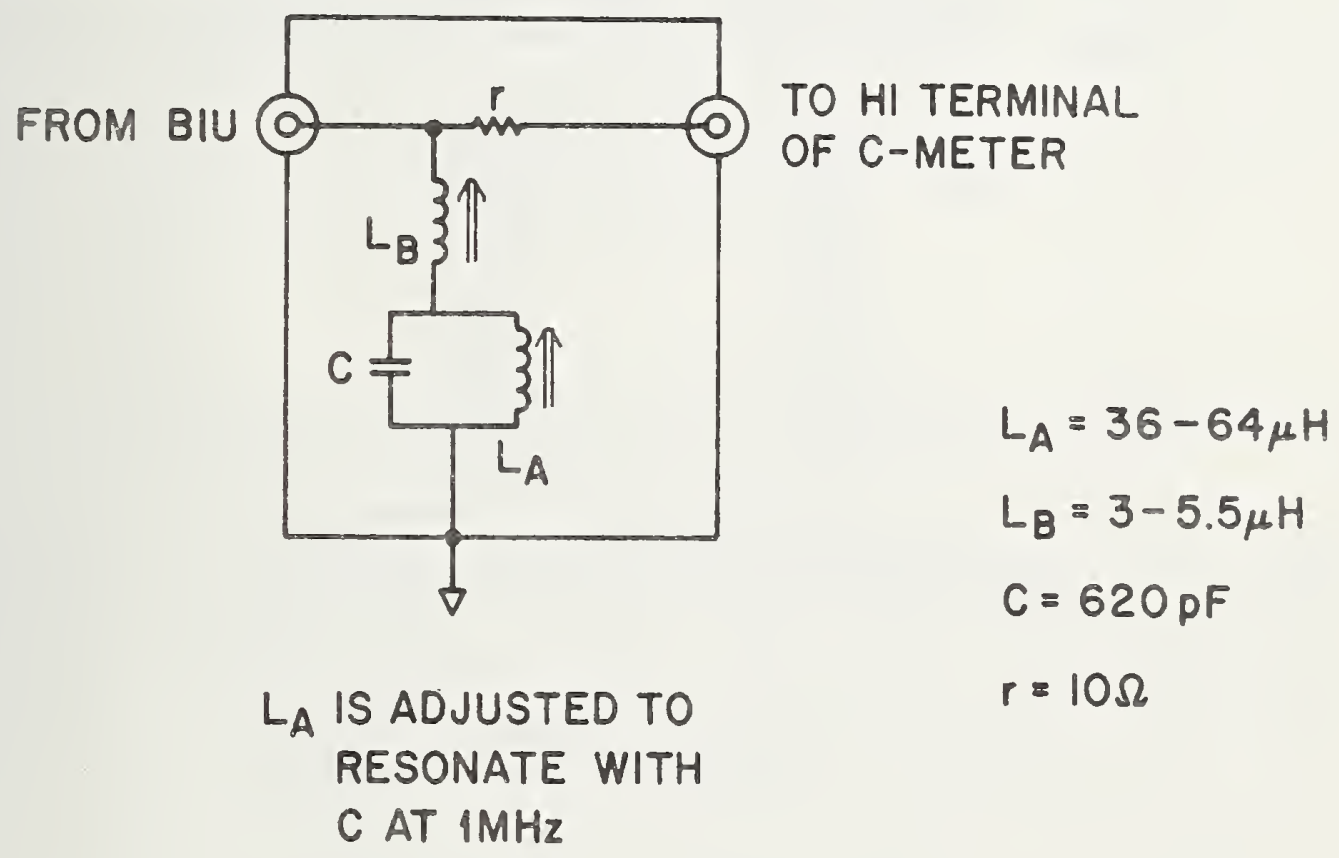

$L_{B}$ IS ADJUSTED TO

PROVIDE MINIMUM

IMPEDANCE AT $3 \mathrm{MHZ}$

FROM BIU TERMINAL

TO GROUND

Figure 13. Schematic circuit diagram of 3-MHz filter. 
It was felt that the best place to eliminate the harmonics was in the $\mathrm{C}$-meter, either in the test signal generator or in the amplifier chain preceding the phase-sensitive detector. Accordingly, arrangements were made with the PAR Corp. to obtain a modified version of the PAR Model $410 \mathrm{C}$-meter with extra filtering to eliminate the unwanted harmonics. The results of a measurement of $S^{\prime}\left(C_{S}\right)$ using the BIU with this C-meter are shown as the filled circles in figure 12. The deviation of $\mathrm{S}^{\prime}\left(\mathrm{C}_{\mathrm{S}}\right)$ from 1.0 is less than $1 \%$ over the range 0 to $200 \mathrm{pF}$. The experimental points do not fall below 1.0 as rapidly with increasing $C_{S}$ as would be expected from eq (6); this is consistent with the behavior expected from a small excess inductance provided by the connecting leads. It is reasonable to expect that similar results could be obtained using the BIU with a BEC Model 72AD C-meter suitably modified to filter out the test signal harmonics.

Table 2. Test-Signal Spectral Analysis for Three C-Meters

\begin{tabular}{cccc} 
& \multicolumn{2}{c}{ Test Signal Component $\left(\mathrm{mV}{ }_{\mathrm{rms}}\right)$} \\
\cline { 2 - 3 } $\mathrm{F}$ (MHz) & BEC Mod.71A & BEC Mod.72AD & PAR Mod.410 \\
\cline { 2 - 3 } 1 & 13.0 & 12.7 & 10 \\
2 & 0.112 & 0.590 & 0.35 \\
3 & 0.050 & 0.063 & 0.400 \\
4 & 0.010 & 0.044 & 0.100 \\
5 & $<0.007$ & 0.050 & 0.112 \\
6 & $<0.007$ & 0.014 & 0.050 \\
7 & $<0.007$ & 0.009 & 0.045 \\
8 & $<0.007$ & 0.009 & 0.040 \\
9 & $<0.007$ & 0.009 & 0.032 \\
10 & $<0.007$ & 0.010 & 0.028
\end{tabular}

These results may be summarized as follows: It has been demonstrated that the BIU can be used with any of three commercially available C-meters at applied voltages up to $10 \mathrm{kV}$. For less than $\pm 1 \%$ error in relative sensitivity $S\left(C_{S}\right)$, the measurable range of $C_{S}$ is from 0 to greater than $400 \mathrm{pF}$; for less than $\pm 1 \%$ error in relative incremental sensitivity $\mathrm{S}^{\mathrm{P}}\left(\mathrm{C}_{\mathrm{S}}\right)$, the measurable range of $\mathrm{CS}$ is from 0 to greater than $130 \mathrm{pF}$.

\section{DISCUSSION AND CONCLUSIONS}

It is useful to consider the results which have been achieved thus far with the BIU and to place them in the broader perspective of the requirements of present and possible future applications.

The two applications of high-voltage capacitance measurements which have already been investigated in some detail are:

(i) measurements of $\mathrm{C}(\mathrm{V})$ of metal-glass-silicon capacitors for the purpose of characterizing the interface between silicon and a passivating glass layer ( $t_{\text {glass }} \approx 10$ to $100 \mu \mathrm{m}$ ), and 


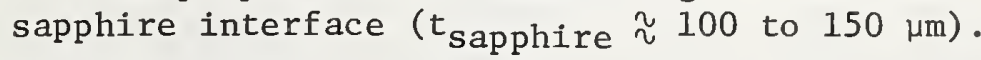

In these applications the range of values of $C_{S}$ encountered was 5 to $55 \mathrm{pF}$. Clearly, the equipment described herein is entirely adequate for these measurements. It is anticipated, however, that future measurement applications (using thicker sapphire wafers) will require biasvoltage capability up to about $\pm 25 \mathrm{kV}$, and current efforts are directed toward the development of equipment that will be capable of operating at these higher voltage levels.

Two other applications have been investigated only in sufficient detail to show that the measurement technique is a useful one. These applications are: (i) characterization of the interface between heavily doped silicon and a thick (>1 $1 \mathrm{~m}$ ) overlying insulator, (ii) measurement of the base-collector capacitance of a very high voltage transistor $\left(\max \mathrm{V}_{\mathrm{c}} \approx 1500 \mathrm{~V}\right)$ in order to nondestructively characterize the doping profile of its base-collector region. Other possible future applications include the characterization of new passivating and encapsulating layers for semiconductor devices (e.g., plastics, resins, and epoxies), studies of the electric field dependence of dielectric polarization under high fields, and studies of dielectric-electrolyte interfaces. In each of these applications, the equipment described appears to be adequate for all current and future applications.

In conclusion:

(1) A technique has been described which allows the safe operation of conmercially available C-meters for capacitance measurements with applied-bias voltage up to $\pm 10 \mathrm{kV}$.

(2) The technique requires a bias-isolation unit for which the circuit, theory, and practical results have been presented.

(3) Details of construction of the bias-isolation unit are provided in the appendix.

\section{ACKNOWLEDGMENT}

I am indebted to Chester J. Halgas for the mechanical design and the construction of the bias-isolation unit described in this report, to Paul Kuczer for construction of an earlier developmental version, and to James M. Breece for assistance with some of the measurements. 
This appendix contains information which is intended for use by anyone who wants to duplicate the BIU described in the body of the report. It consists of:

(i) A list of the mechanical parts which are not commercially available,

(ii) detailed drawings of those parts, and

(iii) a drawing and photographs showing the placement of all parts (the circled numbers refer to the mechanical parts and electrical components identified in tables 1 and 3 ).

Table 3. List of Mechanical Parts

(not commercially available)

Part

No. Part Description

Drawing

1. Front pane1

No.

2. Left side panel

M1

3. Right side panel

M2

Rear panel

M2

4.

5.

Top cover

M3

Bottom cover

M4

6.

Clear acrylic base

M4

7.

8. Peaker/zero-suppression shield

M5

M6

10. Shield cover bracket

M7

11. Mounting bracket for L6, L7

M7

12. Acrylic bias-divider mounting plate

M7

13.

Acrylic front

M9

14.

Acrylic rear

M9

15.

Acrylic left side

M9

16.

Acrylic right side

M9

17.

Peaker/zero-suppression acrylic mounting bracket

M9

18.

Zero-suppression fine-capacitor acrylic mounting bracket

M10

19.

Support

M11

M12

20.

Rectifier mounting plate

M13

21. Zener diode heat sink

M14

22. Peaker/Zero-suppression shield rear insulator

M15

23. Acrylic cover insulator

M16

24. PIN diode heat sink 


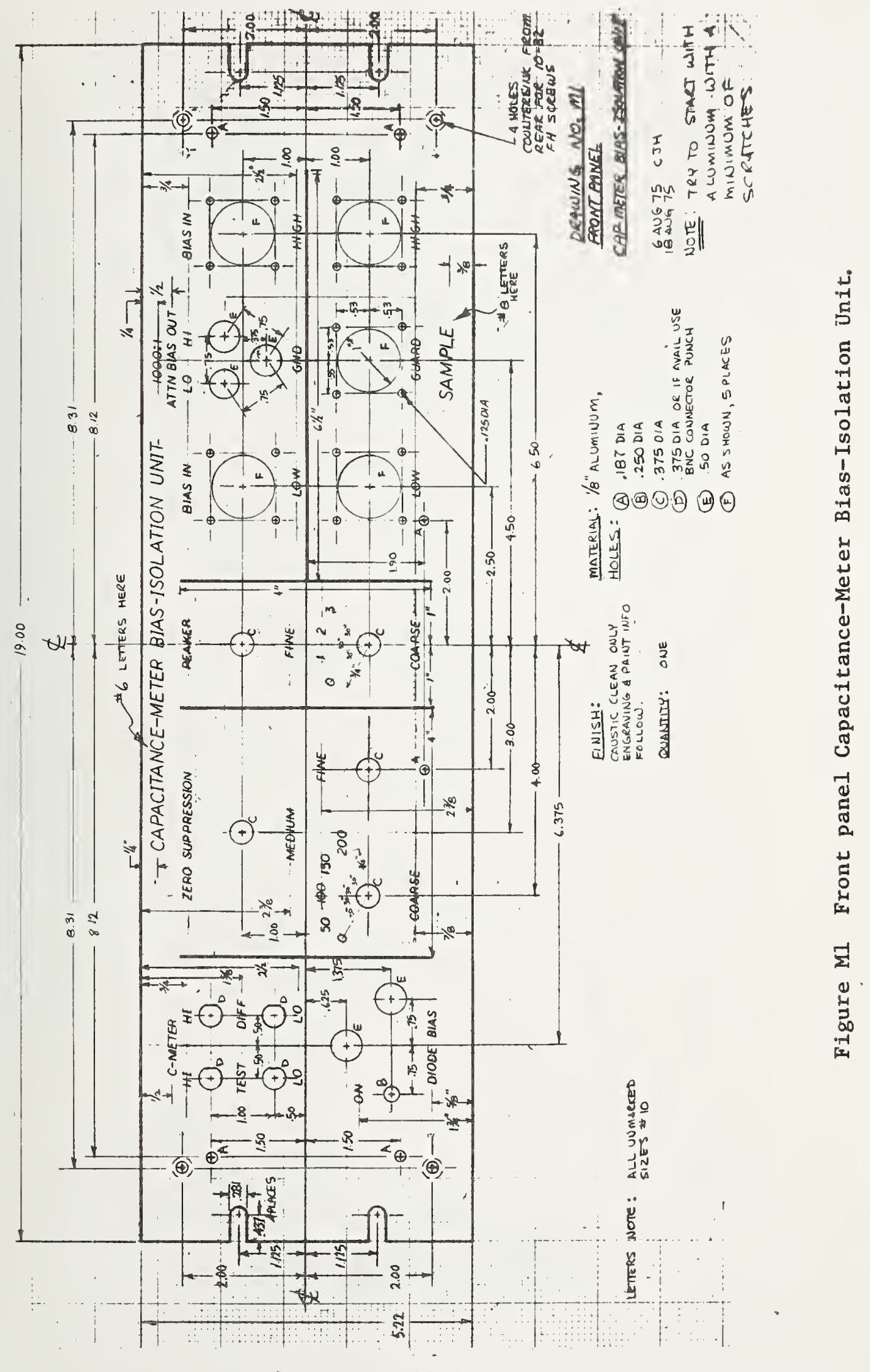




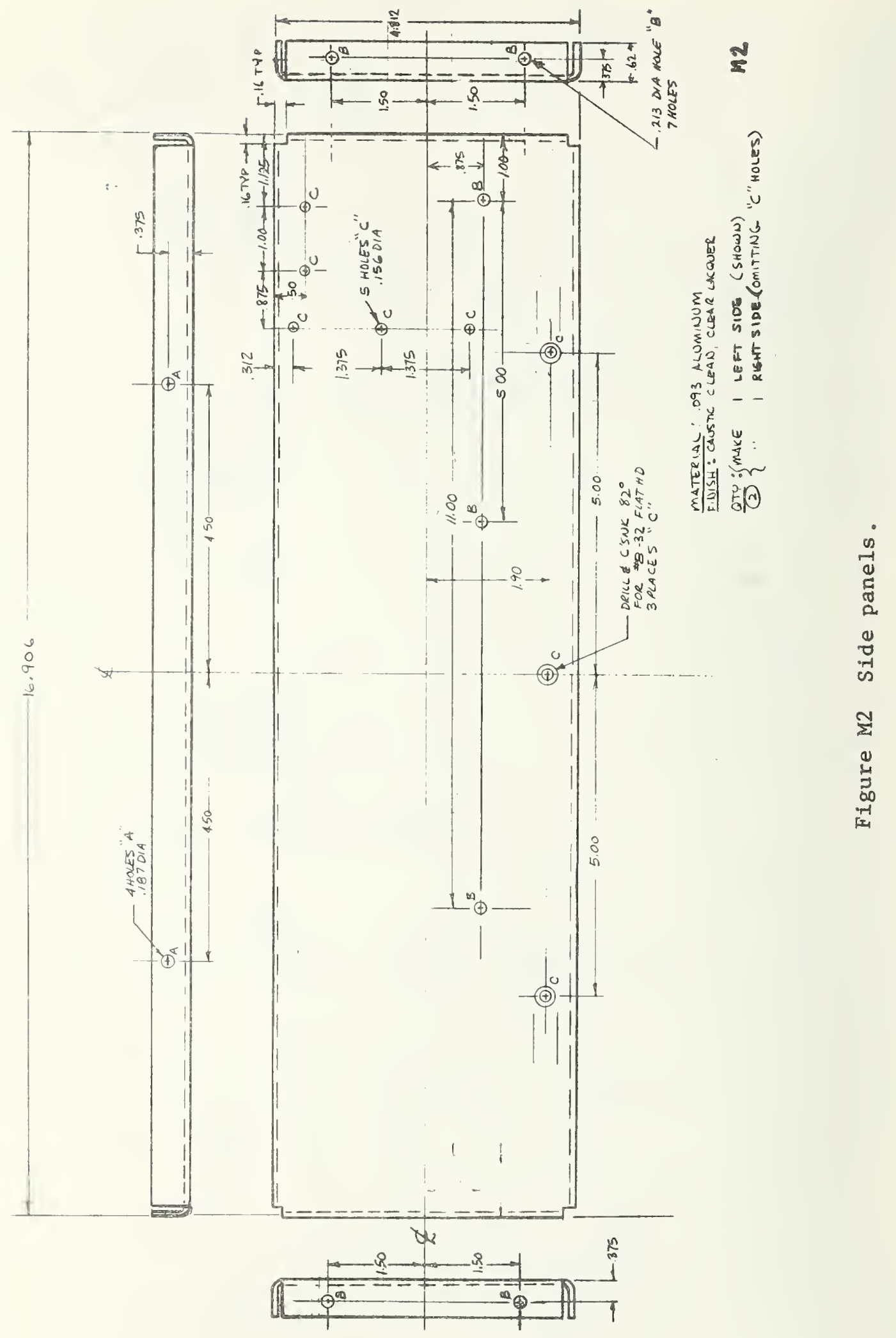




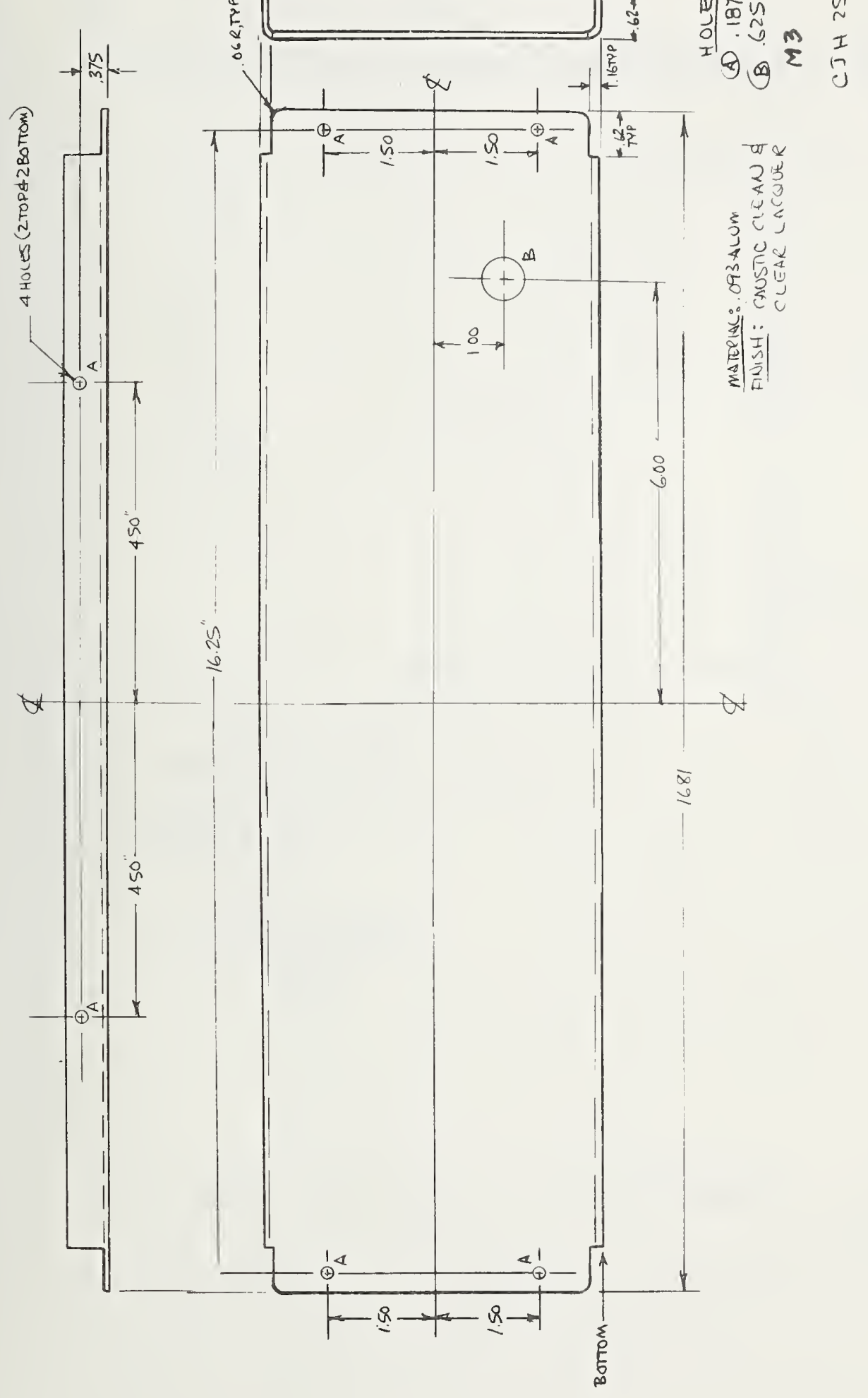

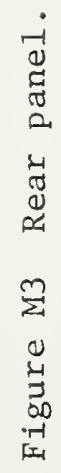




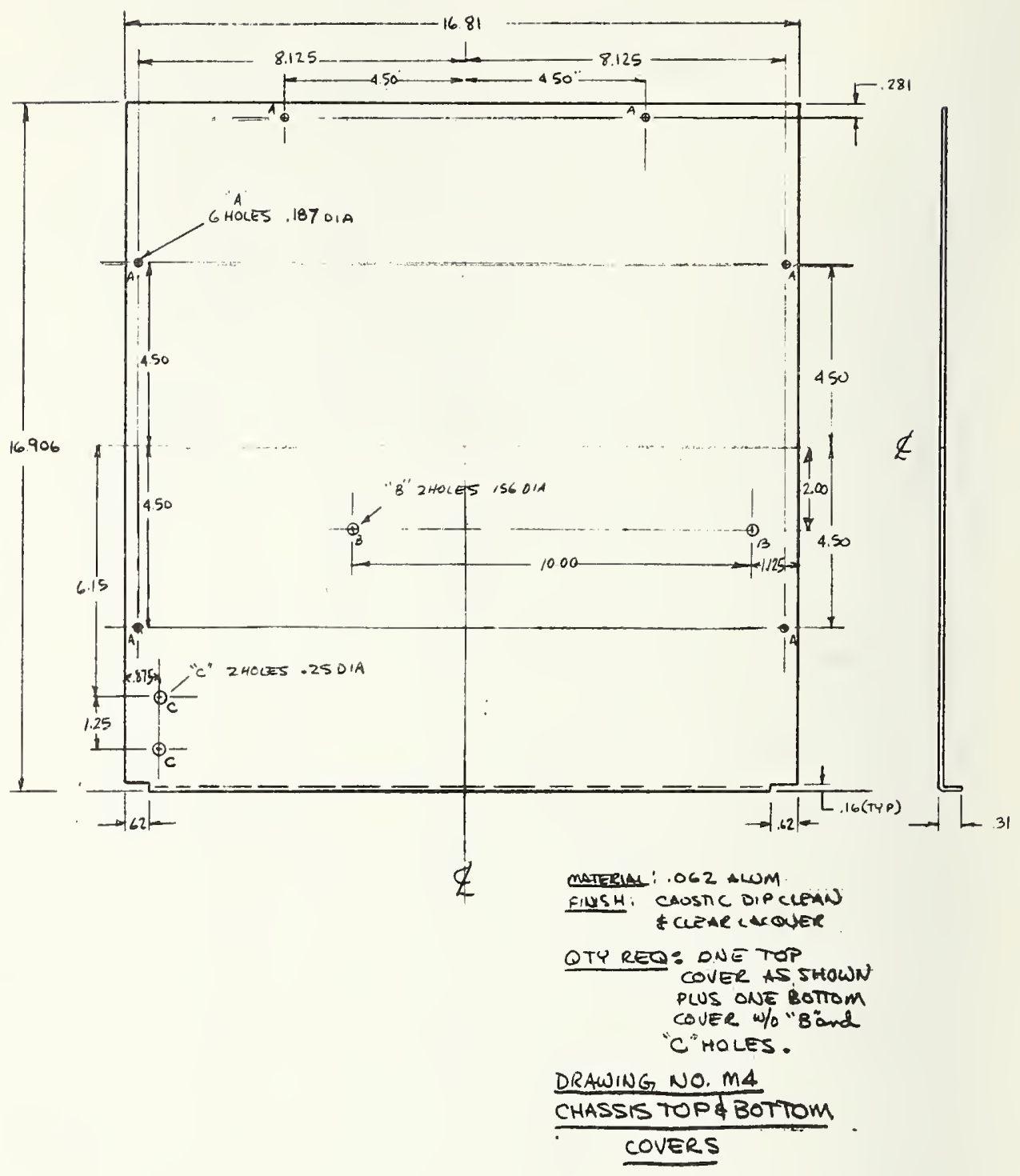

Figure M4 Chassis top and bottom covers. 


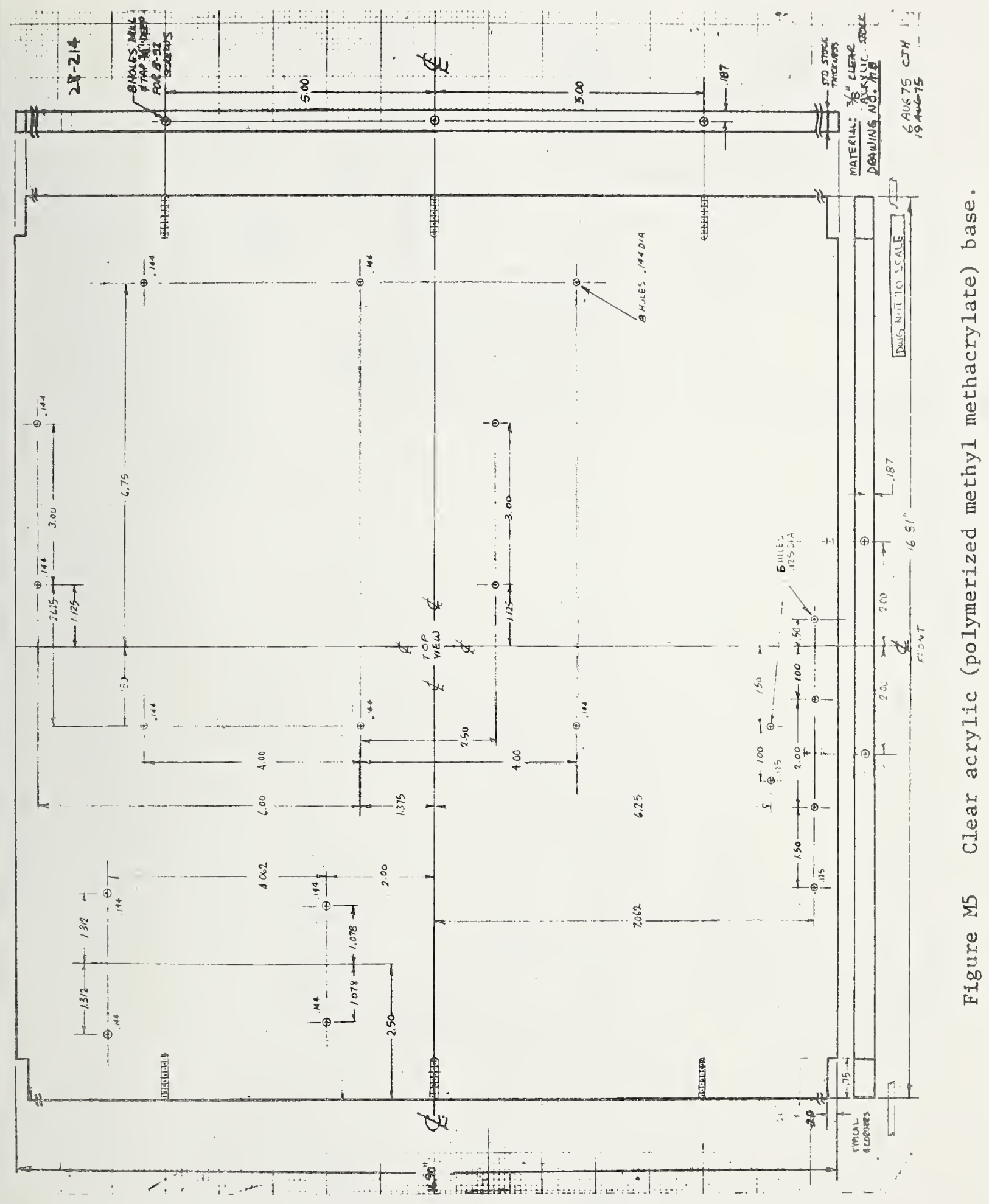




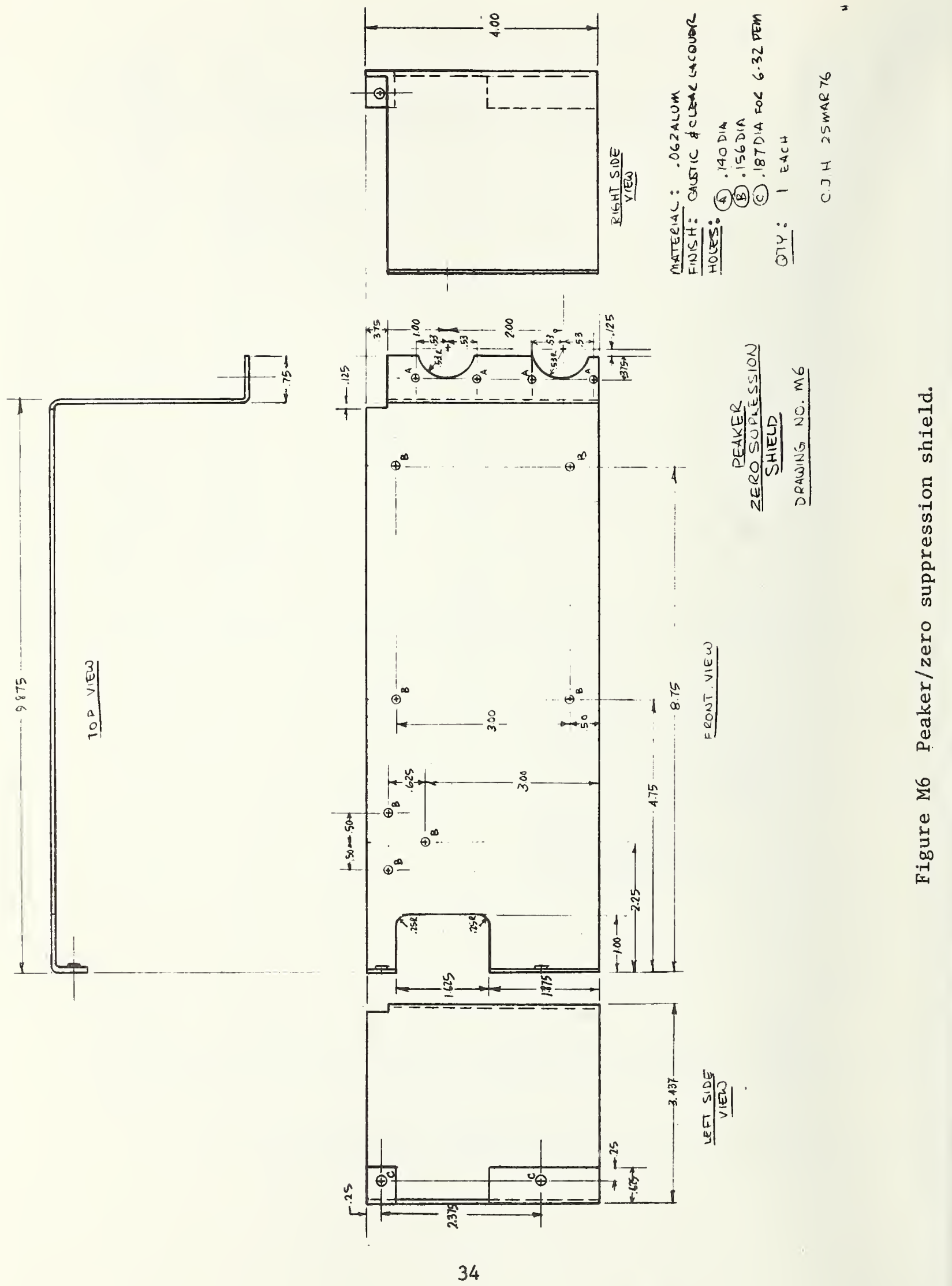



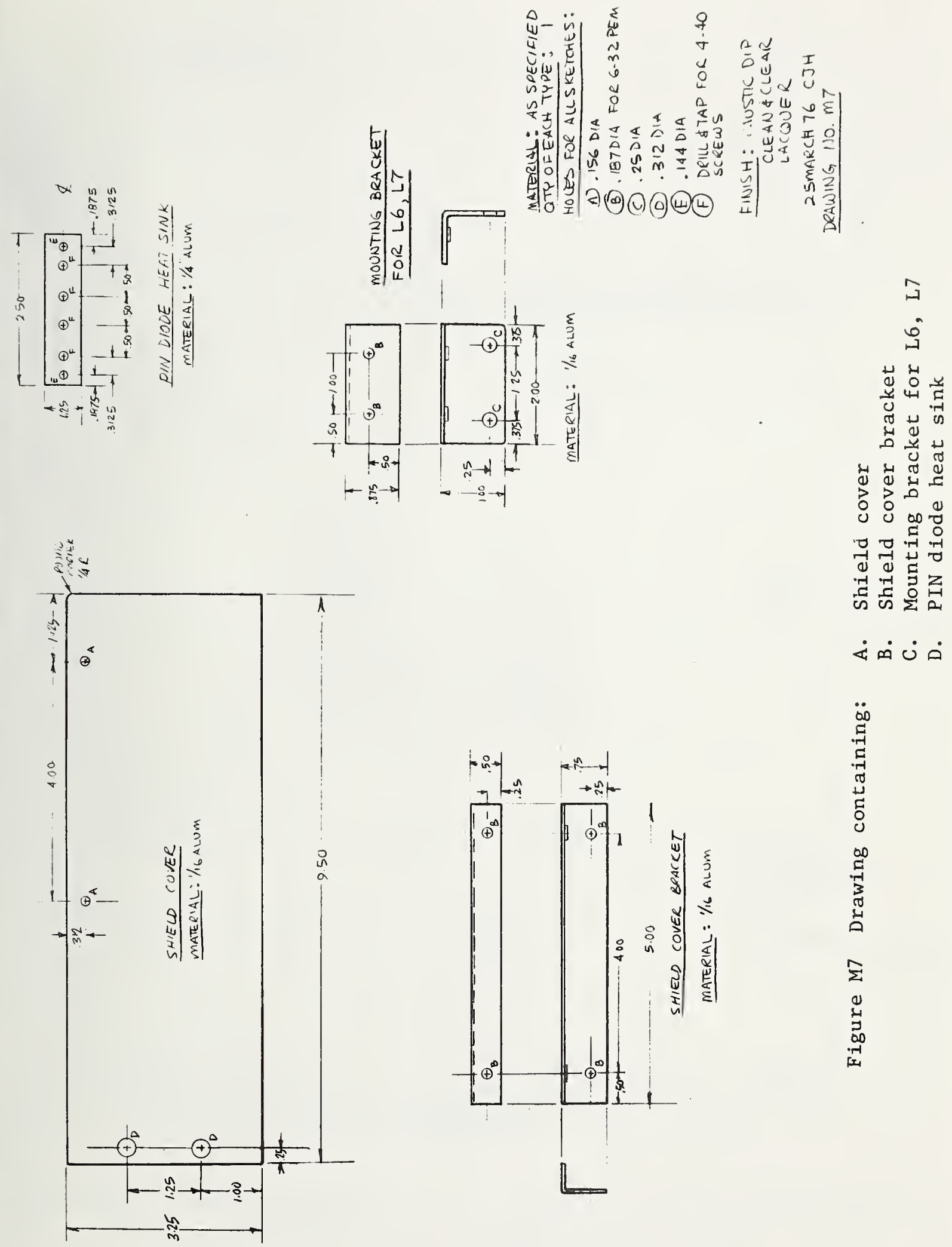

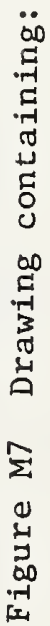




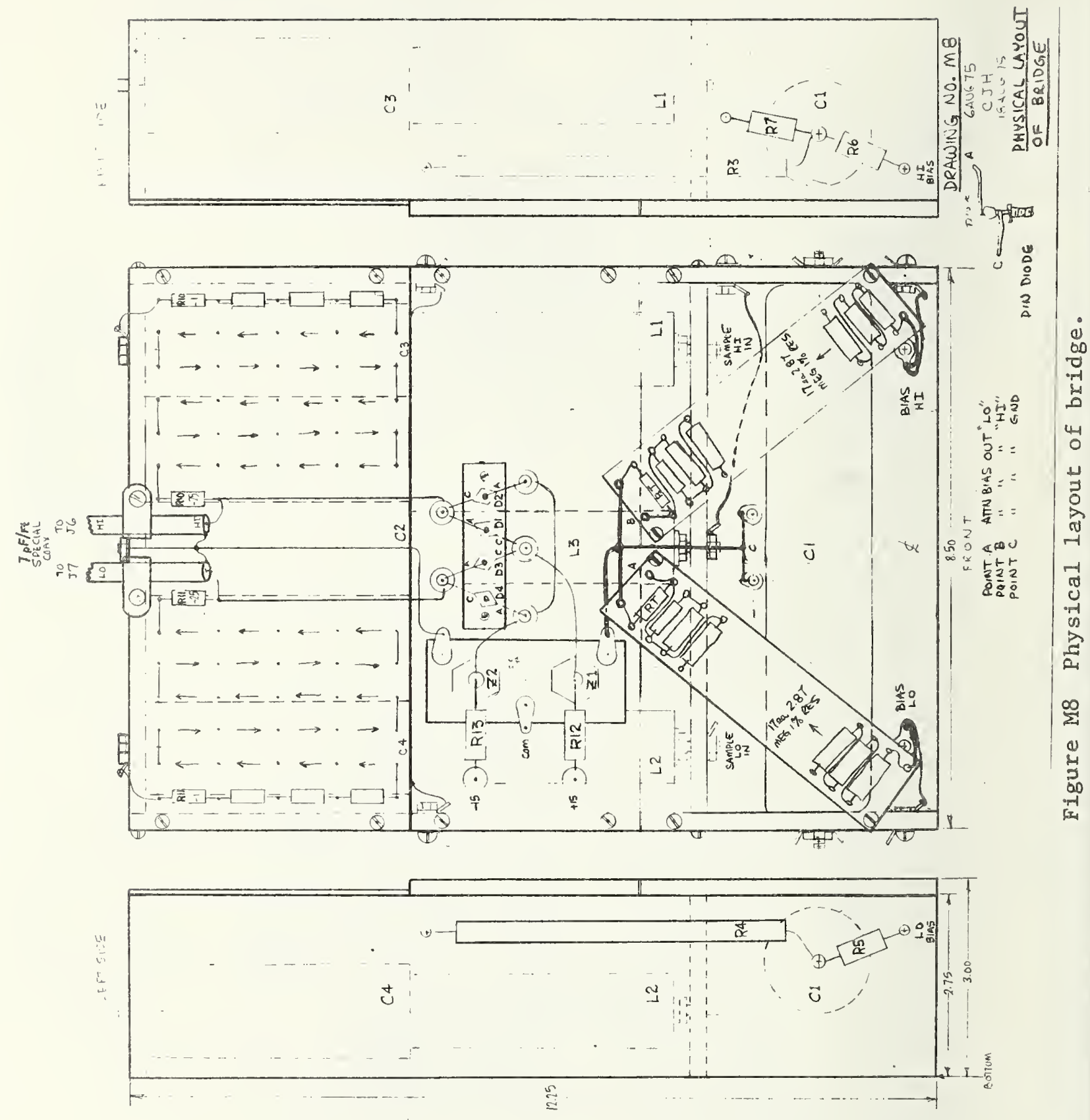



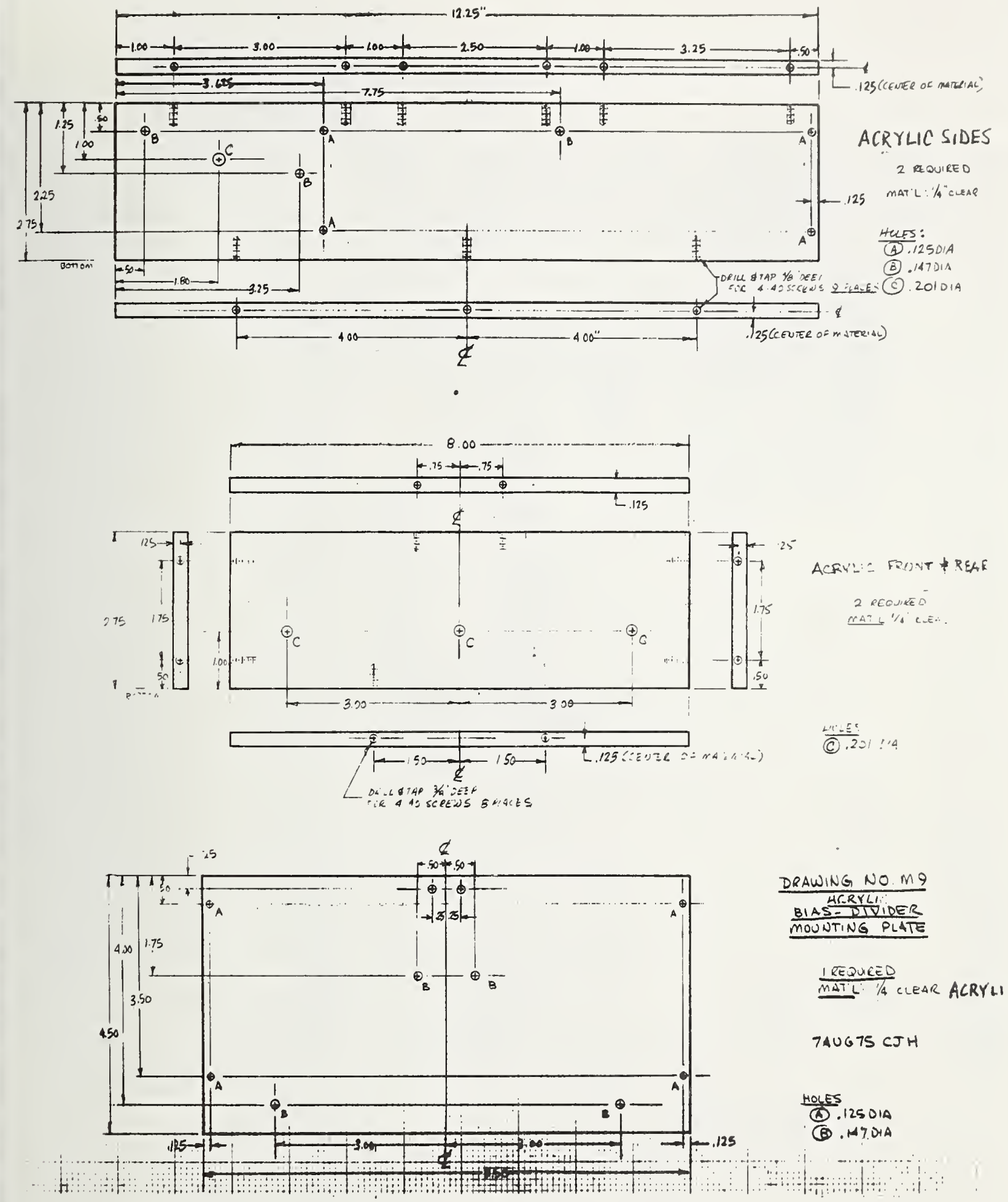
Figure M9 Drawing containing: A. Acrylic bias-divider mounting plate
B. Acrylic front and rear
C. Acrylic sides.




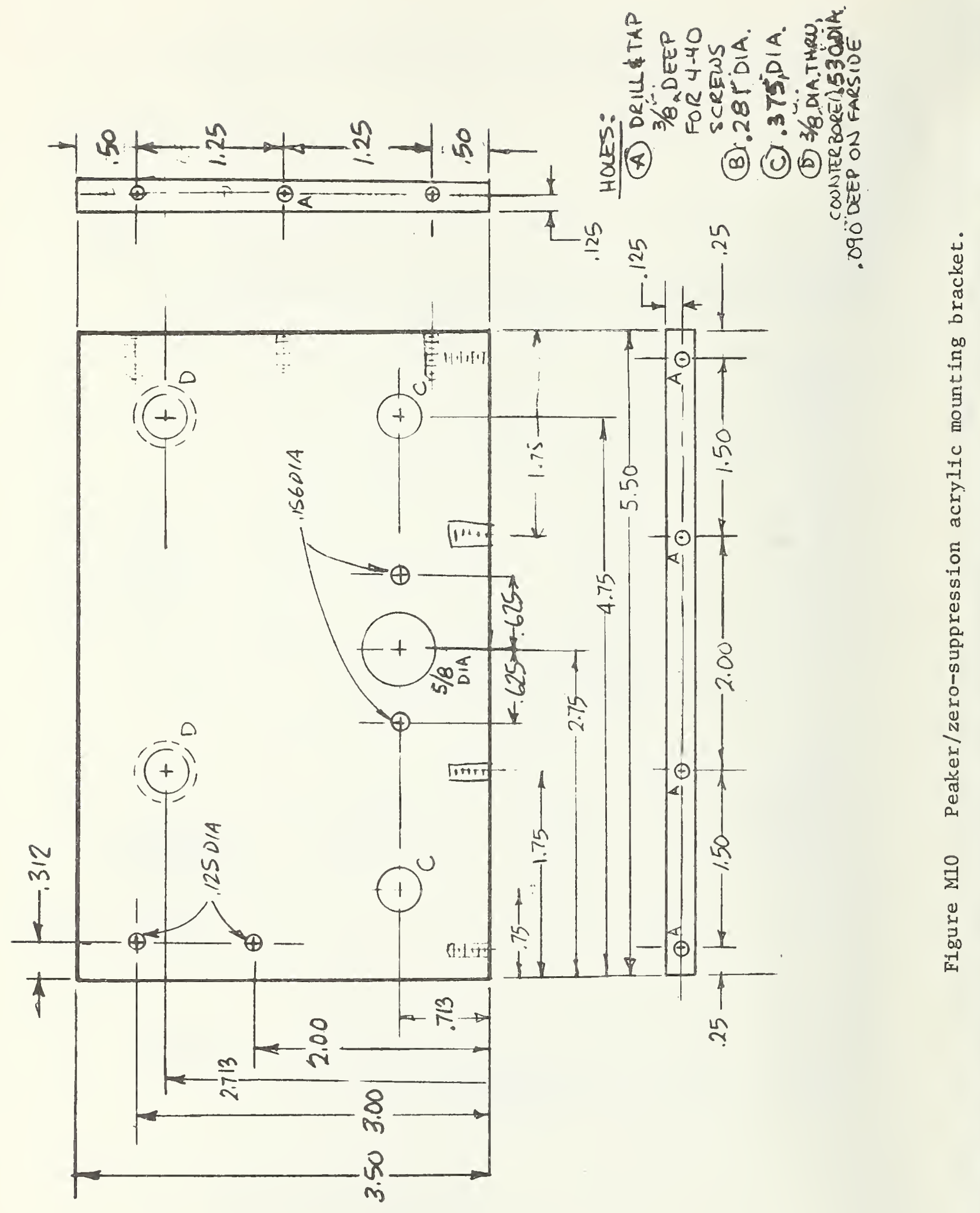




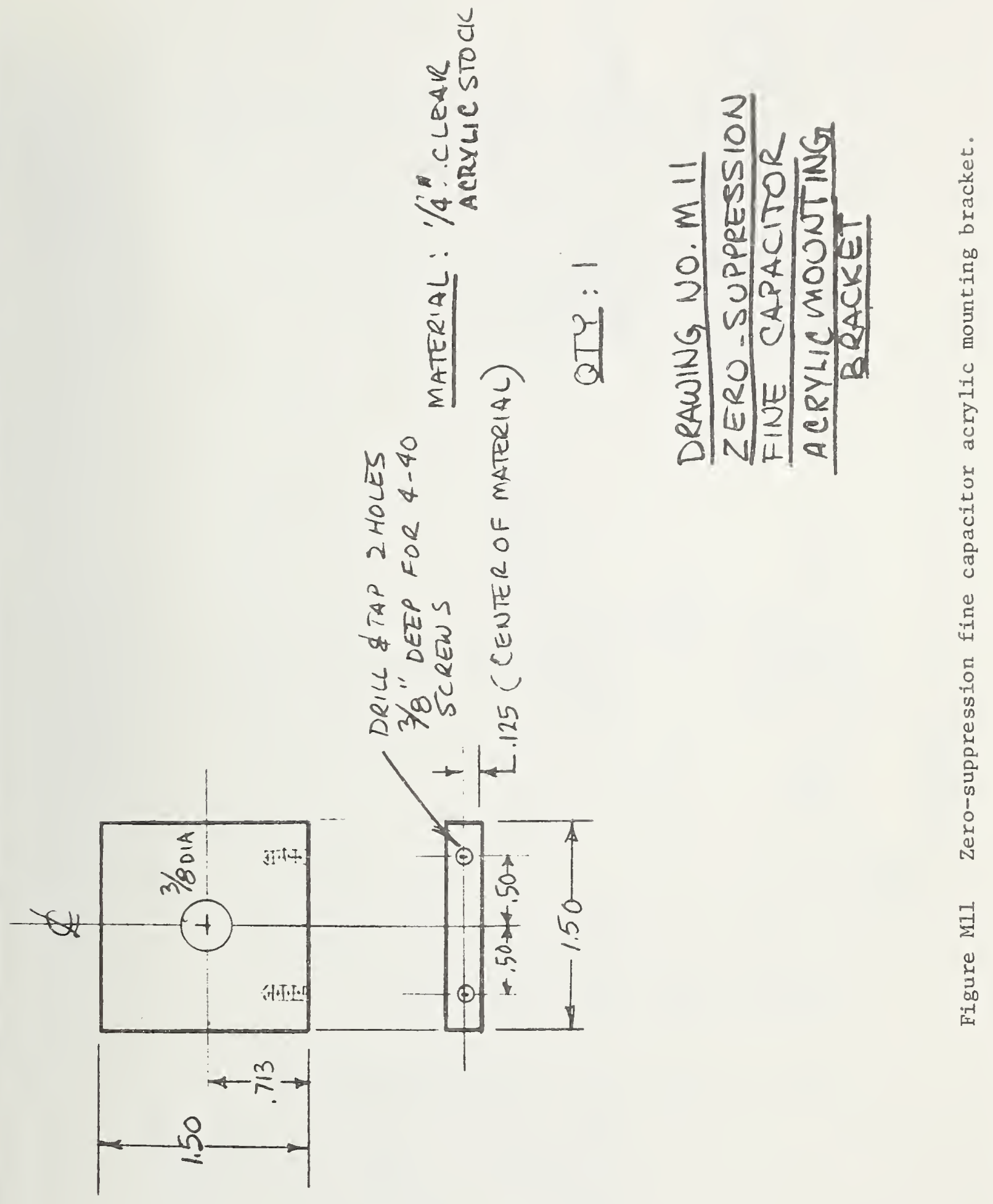



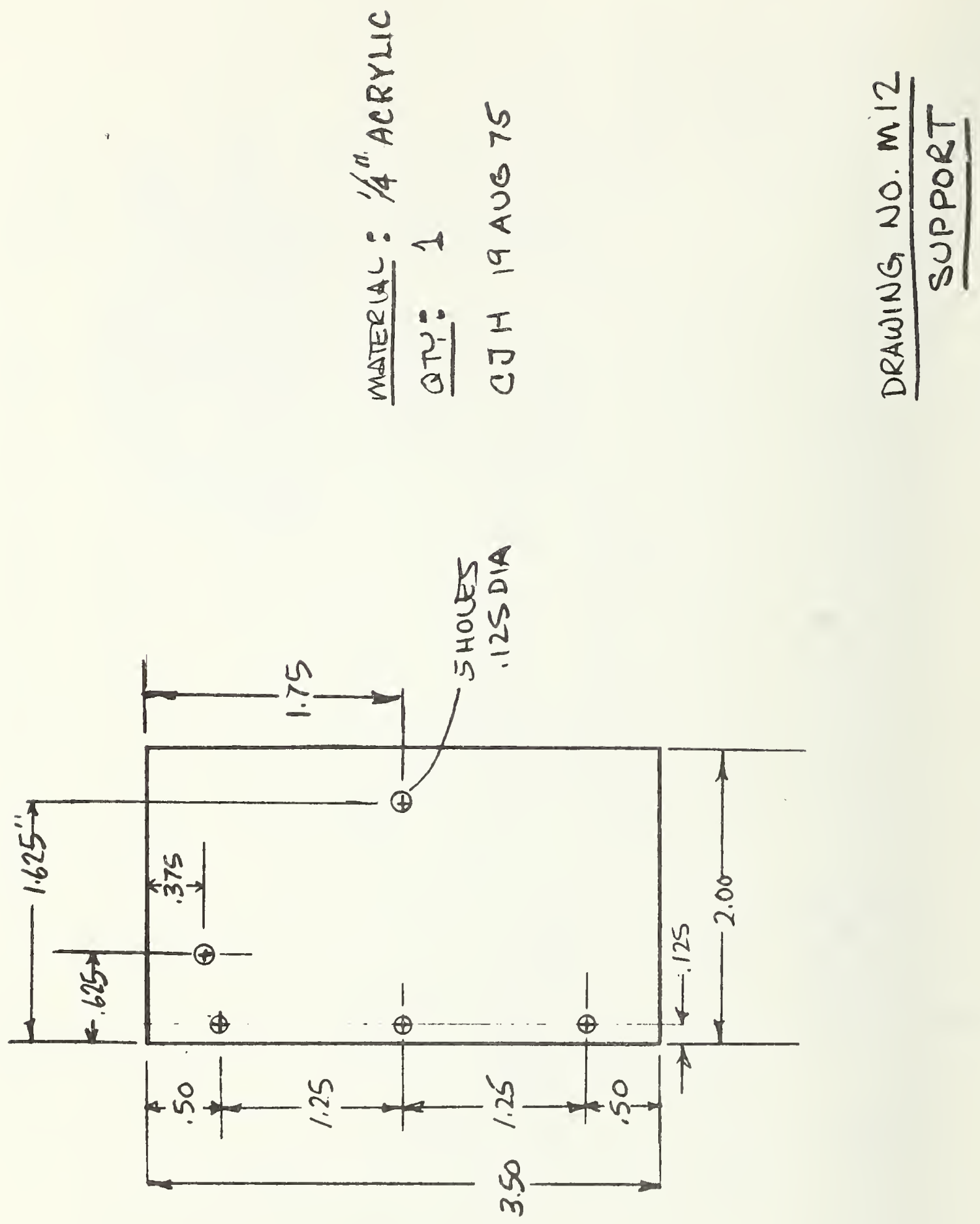


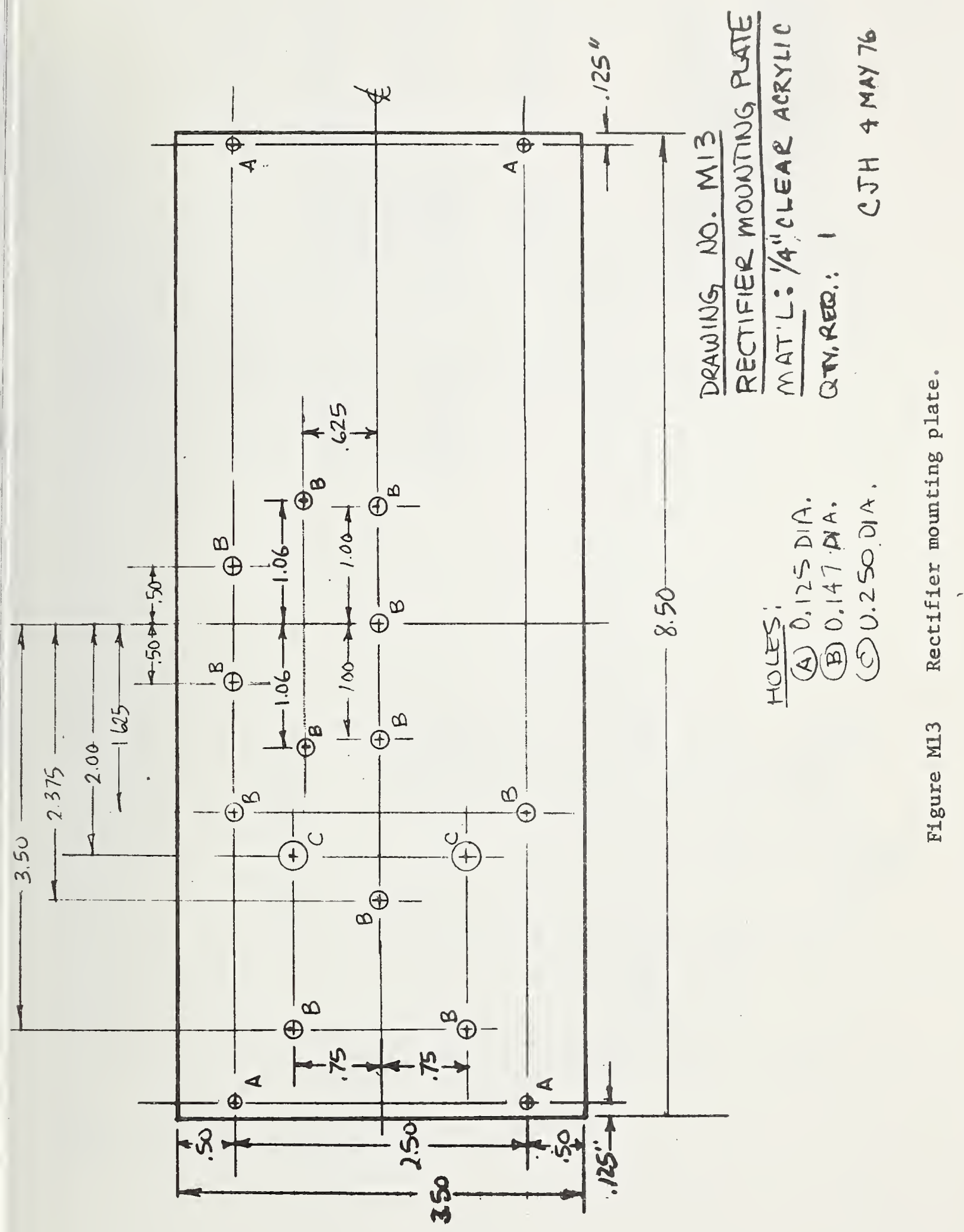



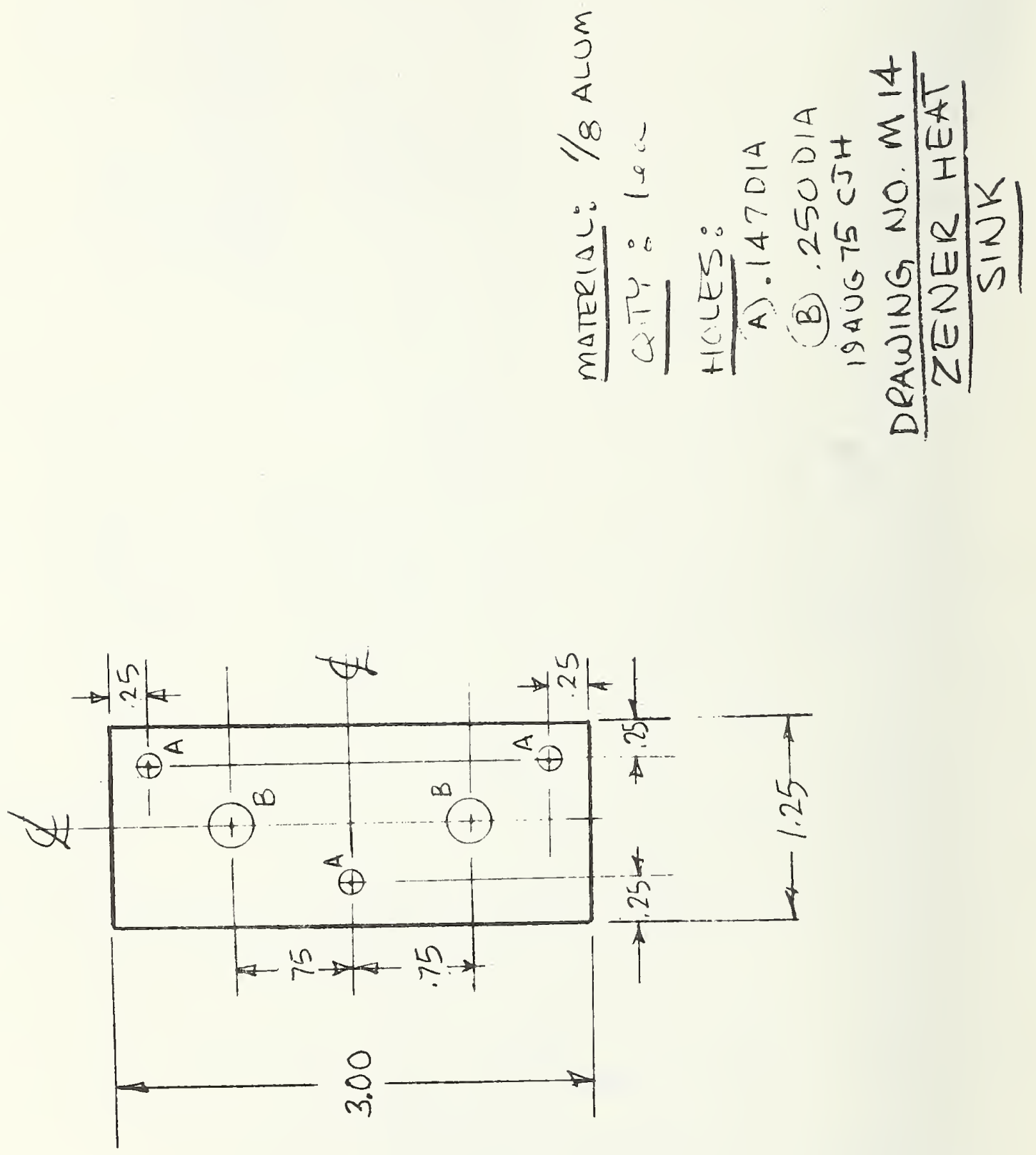

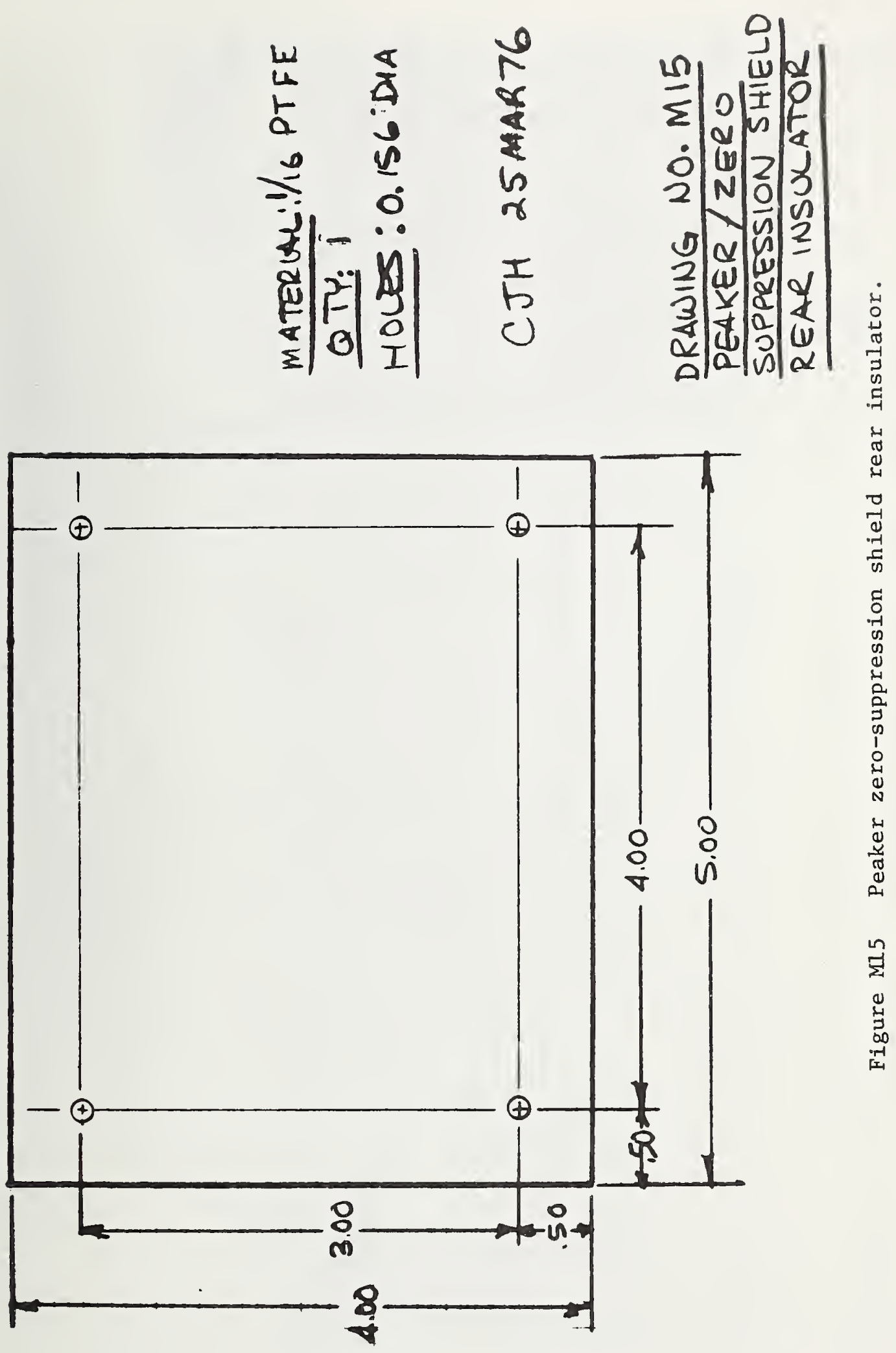


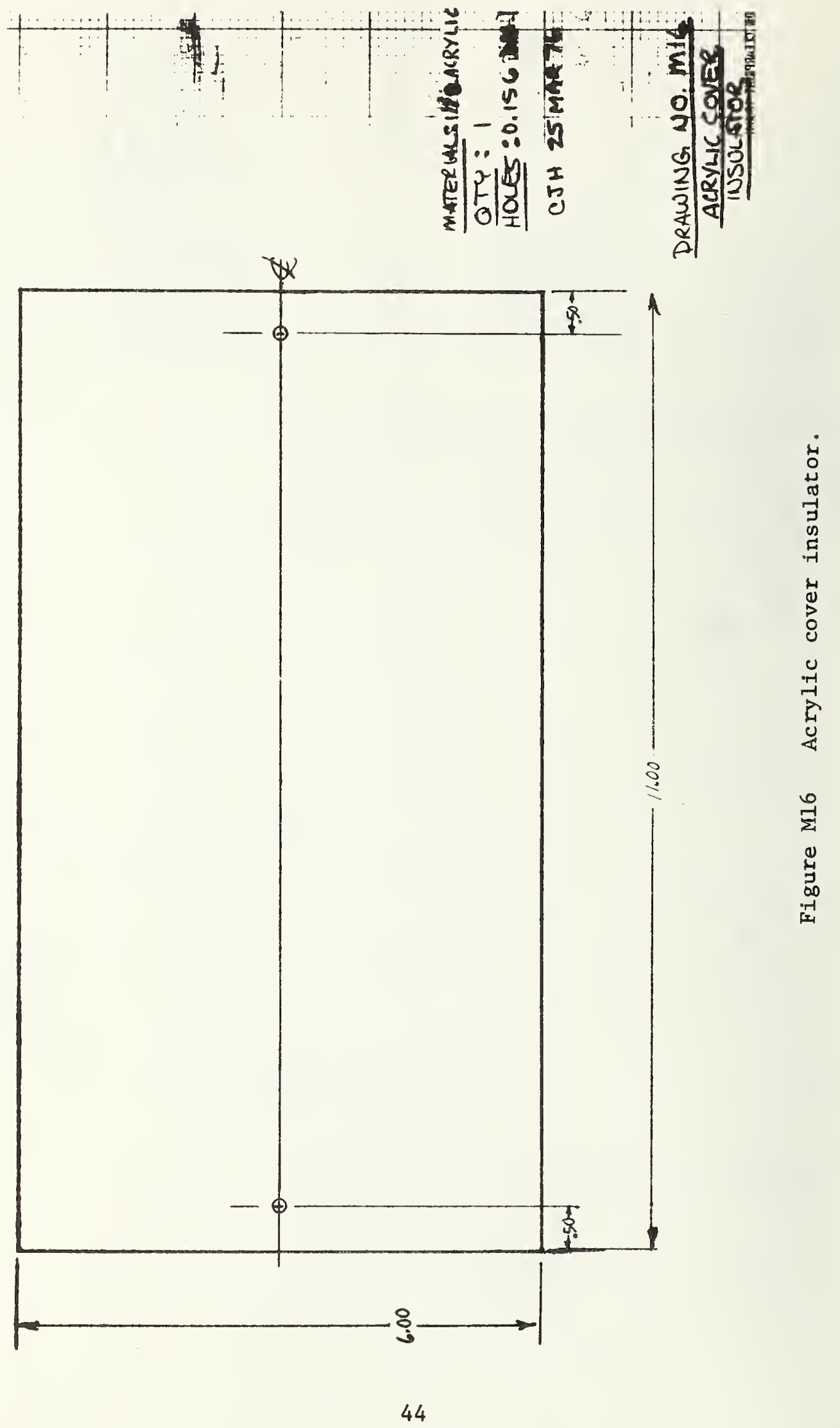




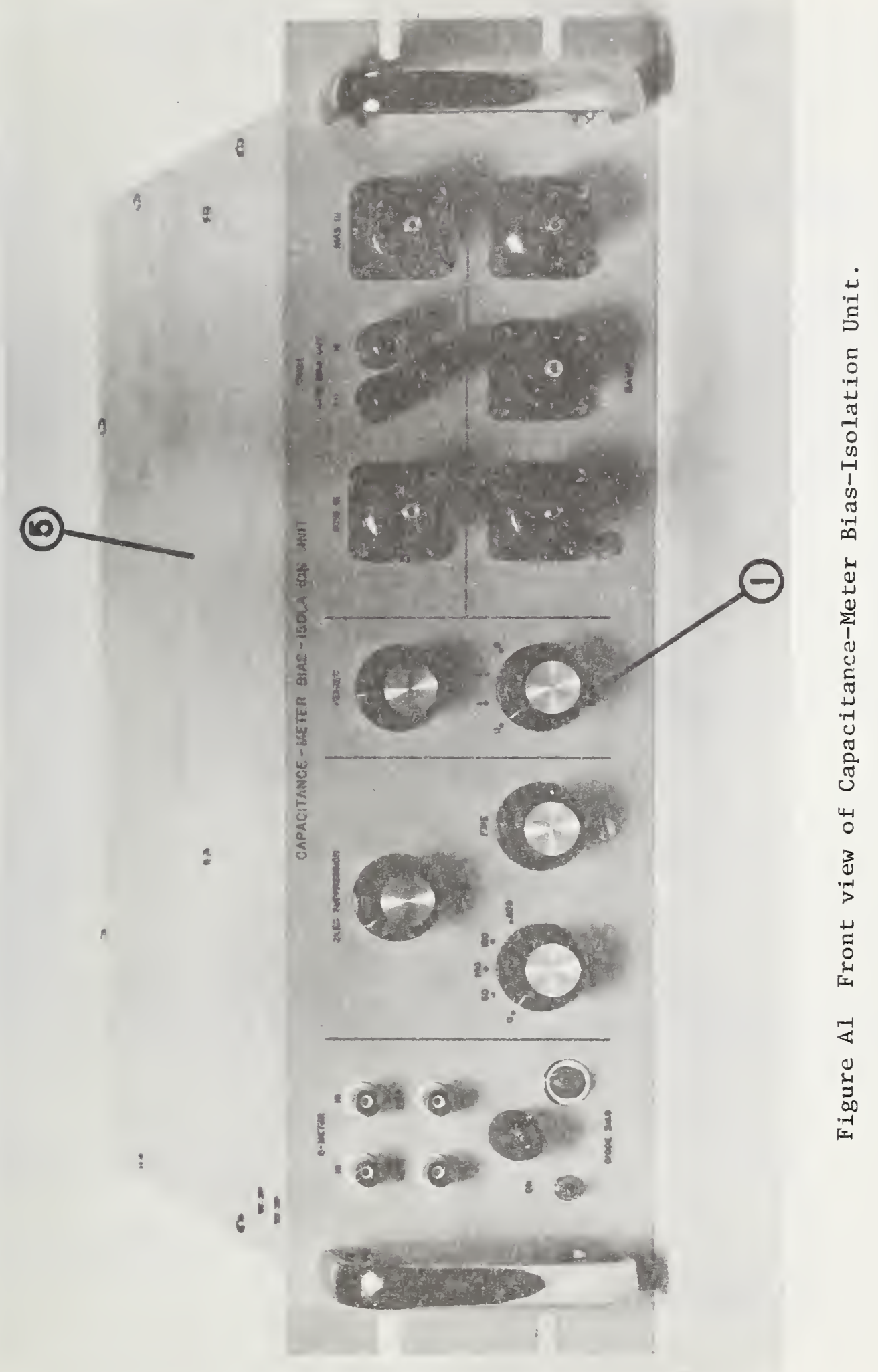




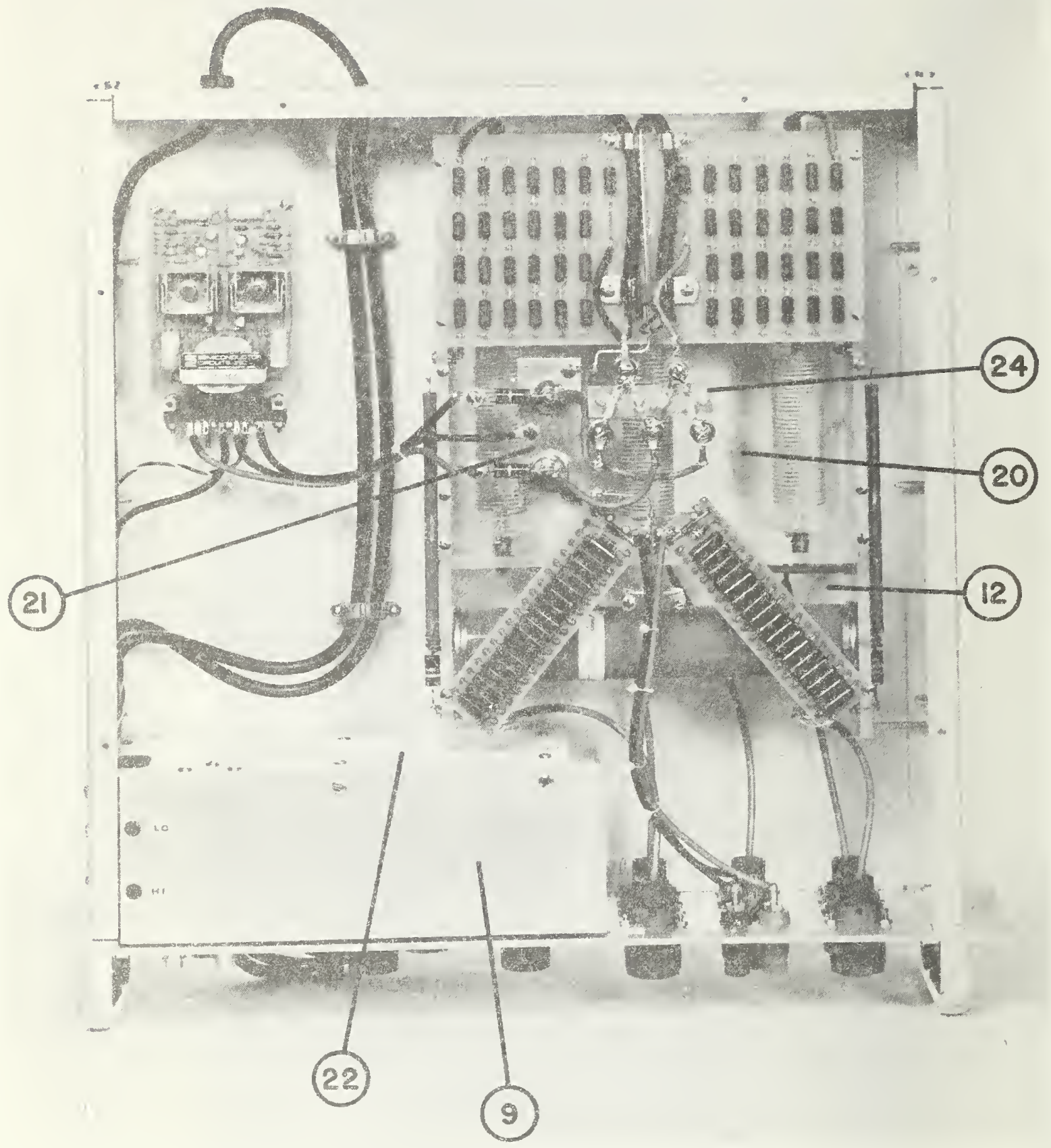

Figure A2 Top view with top cover removed. 


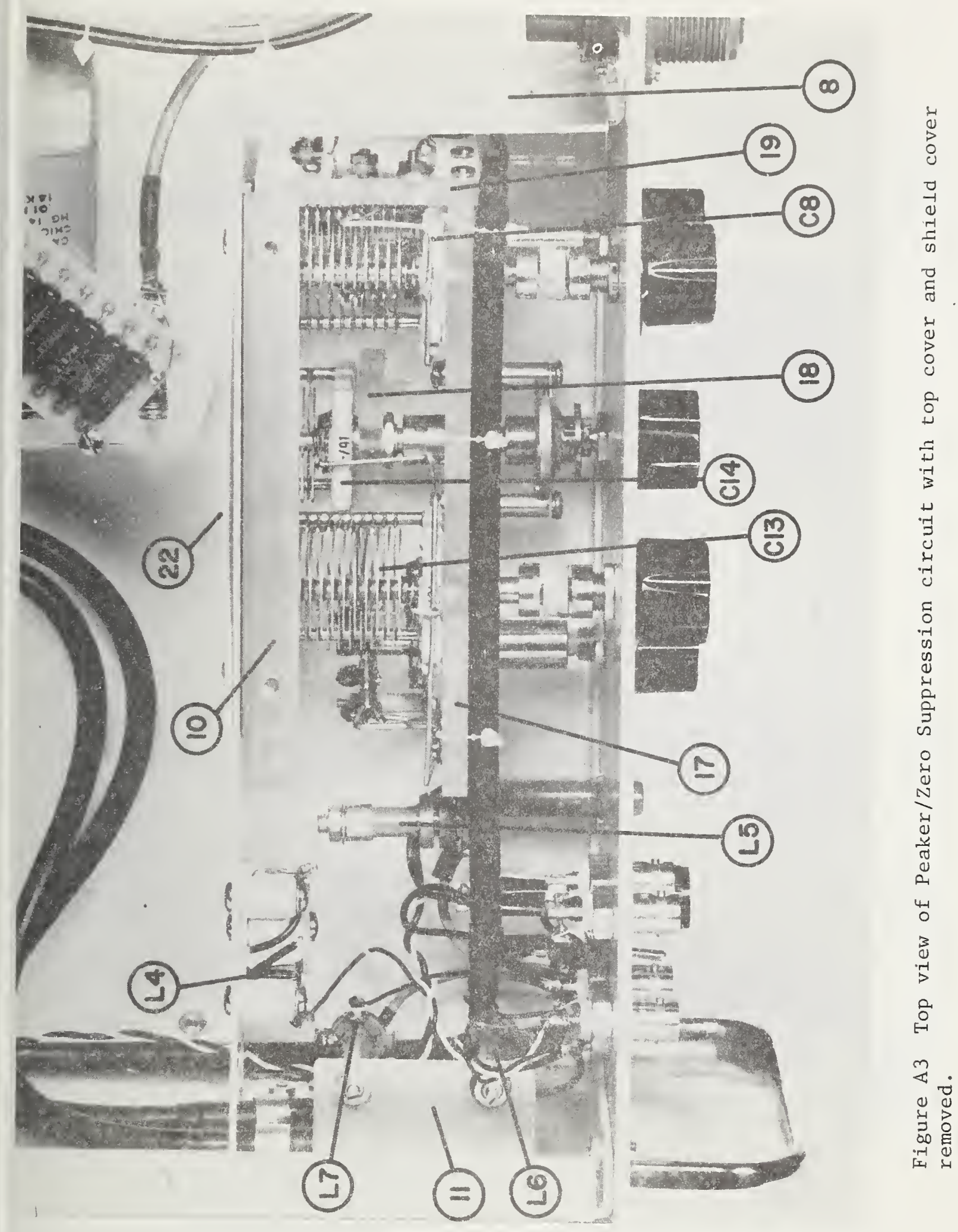




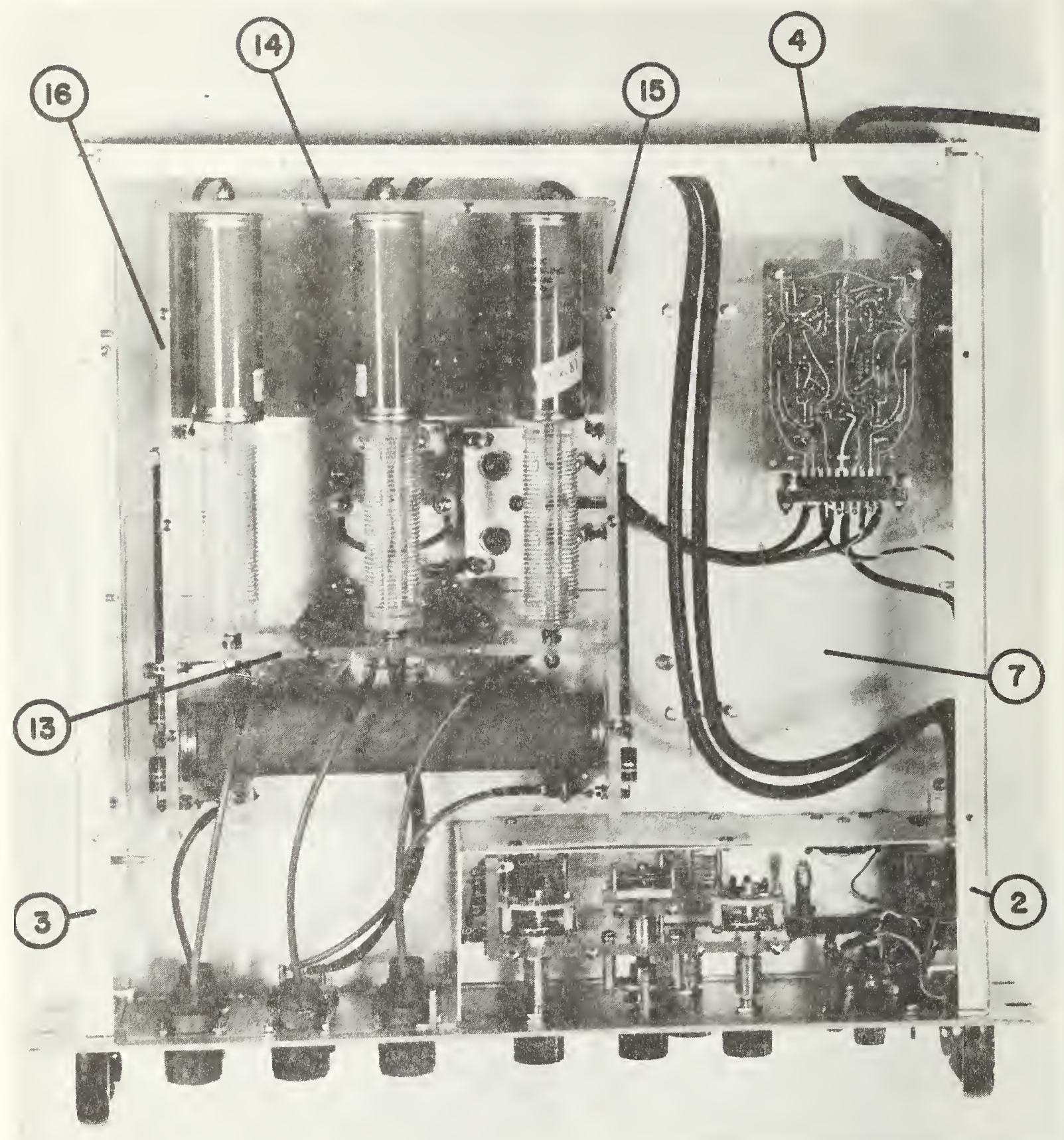

Figure A4 Bottom view with bottom cover removed. 


\section{REFERENCES}

1. Goodman, A. M., A Useful Modification of the Technique for Measuring Capacitance as a Function of Voltage, IEEE Trans. Electron Devices ED-21, 753-757 (1974).

2. Goodman, A. M., An Investigation of the Silicon-Sapphtre Interface Using the MIS Capacitance Method, IEEE Trans. Electron Devices $\underline{E D-22}, 63-65$ (1975).

3. Instruction Manual for BEC Mode1s $71 \mathrm{~A}$ and 71AR Capacitance/Inductance Meter, Boonton Electronics Corporation, Whippany, N.J. 

NBS-114A (REV. 7.73)

U.S. DEPT. OF COMM.
BIBLIOGRAPHIC DATA
SHEET

4. TITLE AND SUBTITLE

\begin{tabular}{|l|l|}
\hline $\begin{array}{l}\text { 1. PUBLICATION OR REPORT NO. } \\
\text { Special Publication 400-34 }\end{array}$ & $\begin{array}{l}\text { 2. Gov't Accession } \\
\text { No. }\end{array}$ \\
\hline
\end{tabular}

Semiconductor Measurement Technology: Safe Operation of Capacitance Meters Using High Applied-Bias Voltage

7. $\operatorname{AUTHOR}(\mathrm{S})$

Alvin M. Goodman

9. PERFORMING ORGANIZATION NAME AND ADDRESS

RCA Laboratories

Princeton, New Jersey 08540

12. Sponsoring Organization Name and Complete Address (Street, City, State, ZIP)

NBS - Washington, D.C. 20234

ARPA - Arlington, Virginia 22209

15. SUPPLEMENTARY NOTES This work was funded by the Defense Advanced Research Projects Agency under ARPA Order 2397, Program Code 6D10. Iibrary of Congress Catalog Card Number: 76-608338

16. ABSTRACT (A 200-word or less factual summary of most significant in formation. If document includes a significant bibliography or literature survey, mention it here.)

The use of capacitance meters (C-meters) to determine small-signal (differentia1) capacitance at $1 \mathrm{MHz}$ as a function of applied-bias voltage is widespread. The maximum value of the bias voltage which may be applied to a samp.le under test with any commer-cially available C-meter is $600 \mathrm{~V}$ or less. A larger bias-voltage capability is required for certain applications.

This report describes a technique for using a commercial C-meter with a Bias-Isolation Unit (BIU) for capacitance measurements at bias-voltage magnitudes up to $10 \mathrm{kV}$ without damage to the measurement equipment. The basic principles of operation and the details of the electrical design of a BIU are discussed.

The use of the BIU imposes certain limitations on the range of sample capacitance which may be measured without introducing excessive error. The theory of these limitations is presented and compared with experimental results obtained from the use of the BIU with each of three commercially available C-meters. The measurement capability demonstrated by these results appears to be adequate for all current and future applications. For less than $+1 \%$ error in the indicated (measured) capacitance, the measurable range of the sample capacitance is found to be from 0 to at least $400 \mathrm{pF}$. In some applications, it is important to be able to accurately measure sma11 changes in the sample capacitance; for less than $\pm 1 \%$ error in the indicated (measured) value of a small change in the sample capacitance, the measurable range of the sample capacitance is found to be from 0 to at least $130 \mathrm{pF}$. Construction details of the BIU are appended.

17. KEY WORDS (six to twelve entries; alphabetical order; capitalize only the first letter of the first key word unless a proper name; separated by semicolons) Bias-Isolation Unit; capacitance measurements at high appliedbias voltage; capacitance-meter; extended-range capacitance measurement; high-voltage C (V) measurements; modified MIS $C(V)$ measurements.
18. AVAILABILITY

$$
\text { X Unlimited }
$$

For Official Distribution. Do Not Release to NTIS

X Order From Sup. of Doc., U.S. Government Printipg Office Washington, D.C. 20402, SD Cat. No. CI3.10:400-34 $\square$ Order From National Technical Information Service (NTIS)
Springfield, Virginia 2215 I

\begin{tabular}{|l|c|}
$\begin{array}{l}\text { 19. SECURITY CLASS } \\
\text { (THIS REPURT) }\end{array}$ & 21. NO. OF PAGES \\
UNCL ASSIFIED & 57 \\
\hline $\begin{array}{l}\text { 20. SECURITY CLASS } \\
\text { (THIS PAGE) }\end{array}$ & $\begin{array}{c}22 . \text { Price } \\
\$ 1.45\end{array}$ \\
UNCLASSIFIED & USCOMM-DC 29042.P74
\end{tabular}




\section{Announcement of New Publications on Semiconductor Measurement Technology}

Superintendent of Documents, Government Printing Office, Washington, D.C. 20402

Dear Sir:

Please add my name to the announcement list of new publications to be issued in the series: National Bureau of Standards Special Publication 400 -.

Name

Company

Address

City State Zip Code

(Notification Key $\mathrm{N}-413$ ) 



\section{PERIODICALS}

JOURNAL OF RESEARCH reports National Bureau of Standards research and development in physics, mathematics, and chemistry. It is published in two sections, available separately:

- Physics and Chemistry (Section A)

Papers of interest primarily to scientists working in these fields. This section covers a broad range of physical and chemical research, with major emphasis on standards of physical measurement, fundamental constants, and properties of matter. Issued six times a year. Annual subscription: Domestic, $\$ 17.00$; Foreign, $\$ 21.25$.

- Mathematical Sciences (Section B)

Studies and compilations designed mainly for the mathematician and theoretical physicist. Topics in mathematical statistics, theory of experiment design, numerical analysis, theoretical physics and chemistry, logical design and programming of computers and computer systems. Short rumerical tables. Issued quarterly. Annual subscription: Domestic, $\$ 9.00$; Foreign, $\$ 11.25$.

DIMENSIONS/NBS (formerly Technical News Bulletin)-This monthly magazine is published to inform scientists, engineers, businessmen, industry, teachers, students, and consumers of the latest advances in science and technology, with primary emphasis on the work at NBS. The magazine highlights and reviews such issues as energy research, fire protection, building technology, metric conversion, pollution abatement, health and safety, and consumer product performance. In addition, it reports the results of Bureau programs in measurement standards and techniques, properties of matter and materials, engineering standards and services, instrumentation, and automatic data processing.

Annual subscription: Domestic, $\$ 9.45$; Foreign, $\$ 11.85$.

\section{NONPERIODICALS}

Monographs-Major contributions to the technical literature on various subjects related to the Bureau's scientific and technical activities.

Handbooks-Recommended codes of engineering and industrial practice (including safety codes) developed in cooperation with interested industries, professional organizations, and regulatory bodies.

Special Publications-Include proceedings of conferences sponsored by NBS, NBS annual reports, and other special publications appropriate to this grouping such as wall charts, pocket cards, and bibliographies.

Applied Mathematics Series-Mathematical tables, manuals, and studies of special interest to physicists, engineers, chemists, biologists, mathematicians, computer programmers, and others engaged in scientific and technical work.

National Standard Reference Data Series-Provides quantitative data on the physical and chemical properties of materials, compiled from the world's literature and critically evaluated. Developed under a world-wide program coordinated by NBS. Program under authority of National Standard Data Act (Public Law 90-396).
NOTE: At present the principal publication outlet for these data is the Journal of Physical and Chemical Reference Data (JPCRD) published quarterly for NBS by the American Chemical Society (ACS) and the American Institute of Physics (AIP). Subscriptions, reprints, and supplements available from ACS, 1155 Sixteenth St. N.W., Wash. D. C. 20056.

Building Science Series-Disseminates technical information developed at the Bureau on building materials, components, systems, and whole structures. The series presents research results, test methods, and performance criteria related to the structural and environmental functions and the durability and safety characteristics of building elements and systems.

Technical Notes-Studies or reports which are complete in themselves but restrictive in their treatment of a subject. Analogous to monographs but not so comprehensive in scope or definitive in treatment of the subject area. Often serve as a vehicle for final reports of work performed at NBS under the sponsorship of other government agencies.

Voluntary Product Standards-Developed under procedures published by the Department of Commerce in Part 10, Title 15, of the Code of Federal Regulations. The purpose of the standards is to establish nationally recognized requirements for products, and to provide all concerned interests with a basis for common understanding of the characteristics of the products. NBS administers this program as a supplement to the activities of the private sector standardizing organizations.

Consumer Information Series-Practical information, based on NBS research and experience, covering areas of interest to the consumer. Easily understandable language and illustrations provide useful background knowledge for shopping in today's technological marketplace.

Order above NBS publications from: Superintendent of Documents, Government Printing Office, Washington, D.C. 20402.

Order following NBS publications-NBSIR's and FIPS from the National Technical Information Services, Springfield, Va. 22161.

Federal Information Processing Standards Publications (FIPS PUBS)-Publications in this series collectively constitute the Federal Information Processing Standards Register. Register serves as the official source of information in the Federal Government regarding standards issued by NBS pursuant to the Federal Property and Administrative Services Act of 1949 as amended, Public Law 89-306 (79 Stat. 1127), and as implemented by Executive Order 11717 (38 FR 12315, dated May 11, 1973) and Part 6 of Title 15 CFR (Code of Federal Regulations).

NBS Interagency Reports (NBSIR)-A special series of interim or final reports on work performed by NBS for outside sponsors (both government and non-government). In general, initial distribution is handled by the sponsor; public distribution is by the National Technical Information Services (Springfield, Va. 22161) in paper copy or microfiche form.

\section{BIBLIOGRAPHIC SUBSCRIPTION SERVICES}

The following current-awareness and literature-survey bibliographies are issued periodically by the Bureau:

Cryogenic Data Center Current Awareness Service. A literature survey issued biweekly. Annual subscription: Domestic, $\$ 20.00$; Foreign, $\$ 25.00$.

Liquified Natural Gas. A literature survey issued quarterly. Annual subscription: $\$ 20.00$.
Superconducting Devices and Materials. A literature survey issued quarterly. Annual subscription: $\$ 20.00$. Send subscription orders and remittances for the preceding bibliographic services to National Bureau of Standards, Cryogenic Data Center (275.02) Boulder, Colorado 80302 . 
U.S. DEPARTMENT OF COMMERCE

National Bureau of Standards

Washington, D.C. 20234

POSTAGE AND FEES PAID

OFFICIAL BUSINESS

U.S. DEPARTMENT DF COMMEACE $C O M=2$ I 5

Penalty for Private Use, $\$ 300$

SPECIAL FOURTH-CLASS RATE

BOOK 